\title{
Acceptability and feasibility of introducing strengthened school- based sexual and reproductive health information and services in Accra, Ghana
}

Terence Adda-Balinia

Population Council

Philip Teg-Nefaah Tabong

Maya Teye

Philip Baba Adongo

Placide Tapsoba

Population Council

See next page for additional authors

Follow this and additional works at: https://knowledgecommons.popcouncil.org/departments_sbsr-rh

Part of the Demography, Population, and Ecology Commons, Family, Life Course, and Society Commons, Gender and Sexuality Commons, International Public Health Commons, Maternal and Child Health Commons, Public Health Education and Promotion Commons, and the Women's Health Commons How does access to this work benefit you? Let us know!

\section{Recommended Citation}

Adda-Balinia, Terence, Philip Teg-Nefaah Tabong, Maya Teye, Philip Baba Adongo, Placide Tapsoba, and Harriet Birungi. 2016. "Acceptability and feasibility of introducing strengthened school-based sexual and reproductive health information and services in Accra, Ghana," STEP UP Research Report. Accra:

Population Council. 


\section{Authors}

Terence Adda-Balinia, Philip Teg-Nefaah Tabong, Maya Teye, Philip Baba Adongo, Placide Tapsoba, and Harriet Birungi 
Acceptability and Feasibility of Introducing Strengthened School-Based Sexual and Reproductive Health Information and Services in Accra, Ghana

TERENCE ADDA-BALINIA, PHILIP TEG-NEFAAH TABONG, MAYA TEYE, PHILIP BABA ADONGO, PLACIDE TABSOBA, HARRIET BIRUNGI 


\section{Acceptability and Feasibility of Introducing Strengthened School-Based Sexual and Reproductive Health Information and Services in Accra, Ghana}

TERENCE ADDA-BALINIA ${ }^{1}$, PHILIP TEG-NEFAAH TABONG ${ }^{2}$, MAYA TEYE ${ }^{2}$, PHILIP BABA ADONGO2 ${ }^{2}$ PLACIDE TABSOBA ${ }^{1}$, HARRIET BIRUNG| ${ }^{1}$

\section{Population Council}

2 School of Public Health University of Ghana, Legon

STEP UP RESEARCH REPORT

June 2016

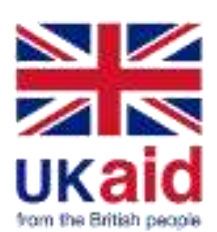


The STEP UP (Strengthening Evidence for Programming on Unintended Pregnancy) Research Programme Consortium generates policy-relevant research to promote an evidence-based approach for improving access to family planning and safe abortion. STEP UP focuses its activities in five countries: Bangladesh, Ghana, India, Kenya, and Senegal. STEP UP is coordinated by the Population Council in partnership with the African Population and Health Research Center; icddr,b; the London School of Hygiene and Tropical Medicine; and Marie Stopes International. STEP UP is funded by UK aid from the UK Government. http://stepup.popcouncil.org

\section{POPULATION COUNCIL \\ Ideas. Evidence. Impact.}

The Population Council confronts critical health and development issues-from stopping the spread of HIV to improving reproductive health and ensuring that young people lead full and productive lives. Through biomedical, social science, and public health research in 50 countries, we work with our partners to deliver solutions that lead to more effective policies, programs, and technologies that improve lives around the world. Established in 1952 and headquartered in New York, the Council is a nongovernmental, nonprofit organization governed by an international board of trustees. www.popcouncil.org

Suggested citation: Terence Adda-Balinia, Philip Teg-Nefaah Tabong, Maya Teye, Philip Baba Adongo, Placide Tabsoba, Harriet Birungi. Acceptability and Feasibility of Introducing Strengthened School-Based Sexual and Reproductive Health Information and Services in Accra, Ghana. STEP UP Research Report. Ghana: Population Council.

(C) 2016 Population Council

Please address any inquiries about STEP UP to the RPC director or Population Council country director: Dr. Harriet Birungi, hbirungi@popcouncil.org

Dr. Placide L. Tapsoba, ptapsoba@popcouncil.org 


\section{Contents}

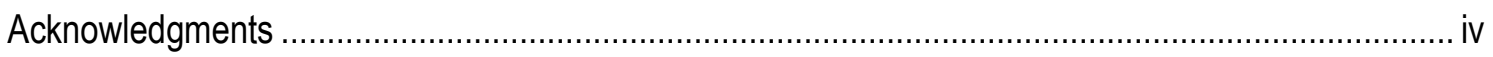

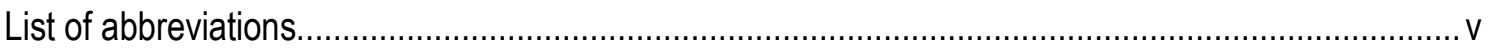

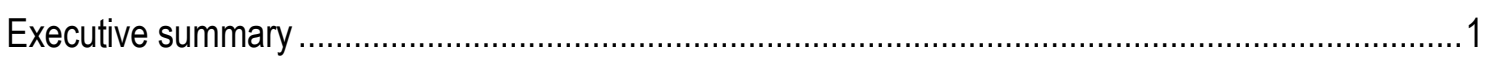

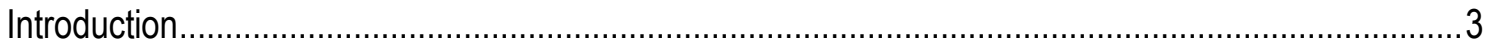

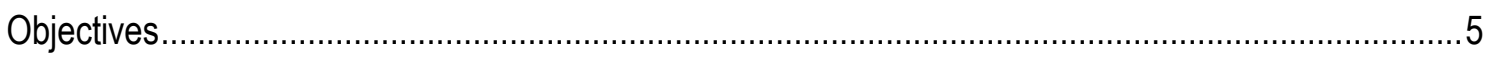

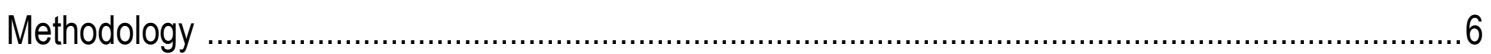

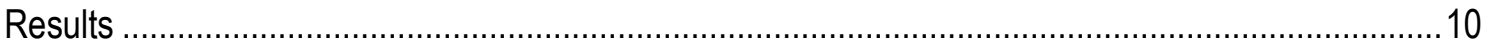

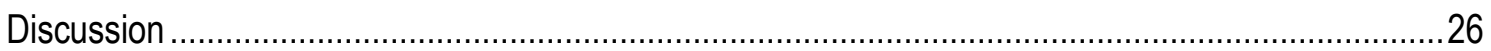

Conclusion

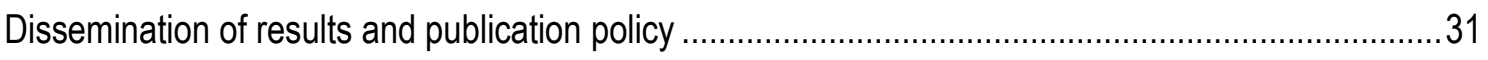

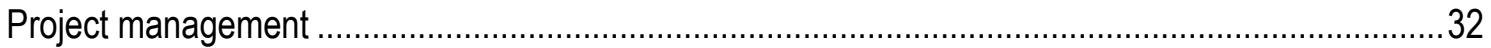

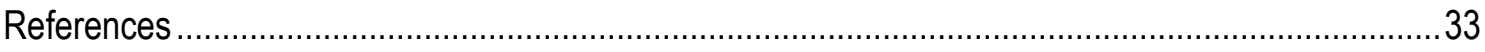

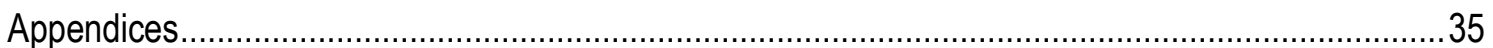




\section{Acknowledgement}

This study is made possible by the DFID funded six-year research program STEP UP (Strengthening Evidence for Programming on Unintended Pregnancy) that aims to accelerates progress toward achieving MDGs 4 and 5 through strengthening evidence-based programming for reducing unmet need for family planning and safe abortion services.

We acknowledge the support of several individuals and organizations who contributed to this study; in particular, staff of Ghana Health Service (GHS) and Ghana Education Service (GES), education experts at UNESCO, DFID, Ghana National Association of Teachers (GNAT), National Population Council (NPC) and the University of Ghana, Legon. Special appreciation to adolescents' boys and girls in Nima Cluster of schools and AI-Waleed Junior High Schools, GHS officials, GES head teachers, teachers, and health services providers, parents/guardians of adolescents in the study sites who provided assistance in the data collection process; research assistants and supervisors who collected data under trying circumstances.

The team is indebted to stakeholders such as the education experts at UNESCO, DFID, Ghana National Association of Teachers (GNAT), National Population Council (NPC) and the University of Ghana, Legon. Its special acknowledgement goes to Dela Kusi-Appouh (PhD), Staff Associate and Gertrude N. Nyaaba (Msc), Programme Officer in Ghana office for the technical support to the Principal Investigator in designing and implementing this study to ensure adherence to agree upon technical and administrative obligations and supervised the analysis and interpretation of study findings.

The authors would also like to thank the STEP UP adolescent study team: Caroline Kabiru, Joyce Mumah, Fauzia Akhter Huda, Anisuddin Ahmed, Francis Onyango and Harriet Birungi for peer support and technical reviews. 


\section{List of Abbreviations}

\begin{tabular}{ll} 
ASRH & Adolescent sexual and reproductive health \\
BECE & Basic Education Certificate Examination \\
DFID & Department for International Development UK \\
FHI 360 & Family Health International 360 \\
FGDs & Focus Group Discussions \\
GES & Ghana Education Service \\
GHS & Ghana Health Service \\
GHS ERC & Ghana Health Service Ethical Review Committee \\
GNAT & Ghana National Association of Teachers \\
HIV & Human Immunodeficiency Virus \\
ICPD & International Conference on Population and Development \\
IDIs & In-depth Interviews \\
IRB & Institutional Review Board \\
JHS & Junior High Schools \\
MOH & Ministry of Health \\
NPC & National Population Council \\
PI & Principal Investigator \\
POP/FLE & Population and Family Life Education \\
PTA & Parent Teacher Association \\
RA & Research Assistants \\
RH & Reproductive Health \\
SHEP & School Health Education Program \\
SRGBV & Sexual and Reproductive Health \\
SRH & Safe Schols Program \\
\hline
\end{tabular}


STEP UP Strengthening Evidence for Preventing Unintended Pregnancies

STIS Sexually Transmitted Infections

UNESCO United Nations Educational, Scientific and Cultural Organization

USAID U.S. Agency for International Development 


\section{Executive Summary}

\section{BACKGROUND}

Young people between the ages of 10-19 years constitute about a quarter of the total population of Ghana. Their knowledge of contraceptive methods has increased substantially over the past two decades. However, many of them have inadequate and inaccurate knowledge about their sexual and reproductive health $(\mathrm{SRH})$ and hence engage in risky sexual behaviors that are detrimental to their sexual health and general wellbeing. An initial study conducted by Population Council under the Strengthening Evidence for Preventing Unintended Pregnancies (STEP UP) project in 2012 assessed the knowledge and Reproductive Health $(\mathrm{RH})$ needs of adolescents living in selected slums in Brong Ahafo and Greater Accra regions with the view of informing an improvement in adolescent sexual health programing in Ghana. The study found that $97 \%(n=626)$ of parents support the provision of SRH information and services in schools when they were asked "Do you think reproductive health information should be provided in schools?" Other key findings from the study include the fact that a third of the sampled adolescents had initiated sex; $80 \%$ of adolescents indicated that they would want more classes on RH in school and among adolescents who had ever had sexual intercourse; and $15 \%$ reported having experienced forced sex. Building on the findings of the above study, a feasibility and acceptability study was conducted to determine the practicality of providing comprehensive inschool ASRH education delivered by psychologists with linkages to outside services.

\section{METHODOLOGY}

The study employed qualitative methods to collect data from key stakeholders in the area of adolescent sexual and reproductive health. We conducted 14 focus group discussions (FGDs): eight FGDs among adolescents aged 12-17 years (groups of 4 boys and 4 girls), four among parents (2 males, 2 females groups) and two among mixed teacher groups. FGDs among adolescent participants were stratified into two groups: participants aged 12-14 years and participants 15-17 years. Four FGDs were held for each of these two groups. In addition, we conducted 18 in-depth interviews among teachers and managers of schools, health workers, clinical psychologists, adolescent sexual and reproductive health programme managers in Ghana Health Service (GHS), Ghana Education Service (GES), UNICEF, UNESCO and the National Population Council (NPC) as well as other development partners in health and education. The interviews were audio recorded and transcribed verbatim. Field notes were also transcribed into the data set. The transcripts were then imported into QSR Nvivo 110 software. Grounded theory approach was adopted for the data analysis and the results presented in narratives supported by illustrative quotes from respondents.

\section{RESULTS}

The study showed that adolescents' existing sources of information on ASRH (such as parents, teachers, peers, media, community members, churches and mosques) presented practical challenges in their application. Social norms especially made it difficult for parents and teachers to freely provide ASRH information. The existing guidance and counselling services in schools which serve as channels for providing education and support on sexual and reproductive health were being undermined by competing roles because counsellors had to still perform their primary role as 
teachers. To that end, respondents generally believed these existing systems were not achieving their objectives, which require a restructuring of the services to make it more comprehensive. The study also showed that both students and parents believed it might be good to use psychologists and health workers to provide school-based sexual and reproductive health to adolescents. However, stakeholders perceived a number of practical challenges around how it could be implemented. Key among the challenges were how to pay for the services that health workers and trained psychologists will render, and the availability of psychologists to cater for all schools. Another important concern raised was the acceptability of certain services such as the distribution of condoms, especially within Missions' Schools which are religiously oriented. Nonetheless, respondents believed that garnering enough support from parents and other stakeholders could make this acceptable. Furthermore, the study found that there was no separate curriculum on population and family life education (POP/FLE); however, some aspects were embedded in existing subjects such as social studies, integrated science and religious and moral education. This notwithstanding, stakeholders perceived the need for a separate subject on POP/FLE which could be made un-examinable as there were already many examinable subjects at the basic and junior high levels. Respondents believed that a stakeholder dialogue could be organized to review the aspects of POP/FLE found in existing subjects such that they could be consolidated into one curriculum to help address POP/FLE issues.

\section{CONCLUSION}

The study concludes that stakeholders generally believed there was the need for enhanced adolescent sexual and reproductive health services in school as the present system of delivering these services were not sufficiently addressing ASRH needs. The use of trained psychologists and health workers were perceived as feasible and acceptable in the Ghanaian context to offer sexual and reproductive health needs of adolescents, provided mechanisms are institutionalized to cater for the financial and other logistical considerations in its implementation. In addition, there were no existing separate curriculum on POP/FLE at the basic and Junior High Schools. Stakeholders believed it was important to consider a dedicated curriculum to specifically address the POP/FLE needs of adolescents. Therefore, developing a separate curriculum for POP/FLE was also perceived to be feasible and acceptable among stakeholders that participated in the study. However, comprehensive stakeholder engagement would be required to determine content and implementation strategies. 


\section{Introduction}

Adolescent sexual and reproductive health (ASRH) is recognized as a key development concern. Globally, adolescents number about one billion, with $70 \%$ living in developing nations (Ayalew, Mengistie, \& Semahegn, 2014). It has been estimated that young people, including adolescents, make up $33 \%$ of sub-Saharan Africa's 973.4 million population. However, that population is expected to continue to increase over the next 35 years (Kabiru, Izugbara, \& Beguy, 2013; World Bank, 2015). A key aspect of adolescents' growth is their sexual development. Adolescents are typically associated with sexual behaviors that negatively influence their sexual development and life later on (Crockett, Raffaelli, \& Moilanen, 2003). While for decades, reproductive health information and service delivery have been identified as necessary programmes for adults, availability of such programs for adolescents has only recently been endorsed. The International Conference on Population and Development (ICPD) held in 1994 and the Fourth International Conference on Women held in 1995 endorsed the rights of young people to reproductive health information and services. Health and development professionals and policy makers are building on this consensus to formulate and deliver needed programmes that are viewed as requiring special designs and broader components to meet adolescents' developmental needs.

Despite this consensus, reproductive health information and services for adolescents remain largely inadequate in sub-Saharan Africa. Policy, cultural and social contexts influence adolescents' access to reproductive health information and services. Many adolescents have an early sexual debut and face difficulties in obtaining reproductive health care. Also, adolescents are typically poorly informed about how to protect themselves from pregnancies and sexually transmitted infections (STIs), which threaten their health and survival. An earlier study found that many adolescent often become pregnant or get infected with sexually transmitted infections because of lack of knowledge on how to engage in safe sex practices (Harden, Brunton, Fletcher, \& Oakley, 2009). Ignorance about sexuality and reproductive health among adolescents has been reported to increase early sexual debut and unplanned pregnancies (Minnick \& Shandler, 2012). The effects of these unplanned pregnancies are manifold and have long lasting consequences on their lives. These adolescents who are the future leaders and potential human resource end up as school dropouts' due to unplanned pregnancy and its complications. Additionally, a good number of adolescents who indulge in early unprotected sex contract HIV and AIDS and STIs (Idele et al., 2014) which can require lifelong medical care and social support from their individual families and the society as a whole.

The introduction of the formal education system shifted the roles of educating and informing adolescents on life skills from the informal educational system to the teacher. Concurrently, schoolbased interventions became logically well-suited to educate young people about pregnancy prevention and equip them with other important life skills. In Ghana, Population and Family Life Education (POP/FLE) was introduced into the basic education system of the Ghana Education Service (GES) between 1973 and 1979 on a pilot basis, re-activated in 1987 and again in 1994. Due to the lack of a comprehensive in-school curriculum and approach to teaching ASRH, the POP/FLE has been unable to achieve its goal to date due to the fragmented approach to teaching, where several subject teachers teach portions of abstinence-only or abstinence- oriented sexual education.

Evidence from previous studies demonstrates the desire for adolescents to receive accurate and more comprehensive sexuality information in schools. An initial study conducted by Population 
Council under the Strengthening Evidence for Preventing Unintended Pregnancies (STEP UP) project in 2012 showed that $80 \%$ (both sexes) of the adolescents interviewed want more classes and information on reproductive health. An earlier survey conducted by Guttmacher Institute also found that the majority (93\%) of adolescents aged 15-19 years surveyed thought it important for sex education to be taught in schools, but far fewer (52\%) ended up receiving it. In addition, an exploratory study in Ghana by the Safe Schools Program (SSP) with funding from USAID identified seven programmatic issues, including the lack of visibility of School-Related Gender Based Violence (SRGBV) on the national agenda as well as big gaps in curricula and teaching regarding gender based violence.

Statistics from the Ghana Health Service (GHS) indicate that 750,000 girls between 15-19 years got pregnant in 2012. Data from the Brong Ahafo Regional Education Directorate revealed that 77 girls were pregnant during the Basic Education Certificate Examination (BECE) examination in 2010, 111 girls in 2011 and 170 girls in 2012, indicating an increasing trend of pregnancies among adolescents in school before completing the UK equivalent of key stage 5 . Evidently, the abstinence only approach to teaching ASRH in schools is not achieving the desired impact. Tied in to this, is the lack of direct linkage with ASRH services in health facilities. This shortfall appears to be a contributing factor to the increasing number of teen pregnancies as observed in Ghana

Opportunities exist to revisit the subject matter to ensure an improvement in the provision of schoolbased adolescent sexual health information and services. For example, the STEP-UP study demonstrated that an overwhelming majority $(97 \%)$ of guardians and community opinion leaders supported the need for sexual reproductive health (SRH) information to be provided in schools. They expressed the need for a comprehensive delivery of sexual and reproductive health services inschool, with the understanding that the majority of Ghana's young people are in school now.

Girls and boys need knowledge and skills related to pregnancy prevention and its implications, while still in school, in order to increase their awareness of possible socio-economic and health consequences of early pregnancy. Comprehensive Sexuality Education (CSE) is defined as an ageappropriate, culturally relevant approach to teaching about sexuality and relationships by providing scientifically accurate, realistic, nonjudgmental information can offers an appropriate platform for providing this information (UNESCO, 2009). Reproductive Health services incorporate a range of activities (e.g. health promotion, prevention, early diagnosis, treatment and care rehabilitation) and the strategies for implementing these activities vary especially for when targeting adolescents. CSE has been reported to have greater impact in addressing the sexual and reproductive health need of adolescents in other countries (Braeken \& Cardinal, 2008; International Planned Parenthood Federation, 2009; McCave, 2007).

We therefore proposed two solutions to strengthening the content and delivery of school sex education: (1) Expanding the current ASRH curriculum by enhancing the content of the existing life skills/POP/FLE education; and (2) Delivering in-school sex education using trained psychologists and providing in-school reproductive health services by health workers.

The first proposed possible solution is to strengthen the content of the existing sexuality education curriculum in line with UNESCO guidance on comprehensive sexuality education and taking into consideration other issues that directly impact adolescent sexual and reproductive health. The proposed strengthened curriculum is expected to include: Human Rights; Gender; Puberty; The Body 
and the Reproductive System; Menstruation; Teenage Pregnancy; Abstinence; Contraception; Abortion; Sexually Transmitted Infections (STIs); HIV and AIDS; Romantic Relationships and Communicating about Sex and Reproductive Health; and Sexual Harassment and Gender-Based Violence. Specifically, such a curriculum should be designed to ensure that it improves adolescent's knowledge on contraception and health consequences of adolescent pregnancy. The strengthened curriculum will also emphasize gender issues including prevention and responses to gender based violence. In the initial diagnosis study, about $15 \%$ of adolescents who had ever had sex reported having experienced forced sex. Hence, efforts will generally aim at reducing the prevalence and impact of gender based violence by enhancing young people's knowledge of and access to support systems including early warning signs of violence or high-risk factors for its occurrence.

Our proposed second solution is based on the premise that trained psychologists are equipped with the requisite skills to deliver, evaluate, diagnose, treat, and study human behaviour and thus would be able to deliver and explain comprehensive sexuality education to adolescent students in a much more participatory and holistic manner than the current approach where sexuality education is being taught by teachers. This is because studies have showed that the behaviour during the adolescent period is heavily influenced by a range of psychological factors (Coley, Votruba-Drzal, \& Schindler, 2009; Kincaida, Jones, Sterrettb, \& McKeec, 2012). It will also be relatively easier for psychologists to identify and assist any adolescent students who have experienced any gender-based violence. We also propose the linking of adolescents to health services in schools and health services outside the school. This will make health workers and services more accessible to adolescents and thus provide practical solutions for adolescents who seek information and services. We propose that nearby clinics could provide adolescent outreach services on selected days and thus enable adolescents to access information and services in school without fear of being stigmatized.

To ascertain the acceptability and feasibility of the two proposed solutions to strengthen school-based sexual and reproductive health information and services, we conducted qualitative interviews with various stakeholders.

\section{Objectives}

The overall objective of the study was to assess the acceptability and feasibility of two proposed solutions for strengthening the programme content and delivery of in-school sexual and reproductive health programmes in Ghana.

Specific objectives were to:

- Assess the acceptability of an enhanced curriculum for POP/FLE among education sector stakeholders in Ghana;

- Assess the acceptability and feasibility of delivering SRH information and services in schools by trained psychologists and health care providers, respectively, among stakeholders;

- If deemed acceptable, determine the system changes needed to implement the proposed interventions (enhanced curriculum and using psychologists and health care providers) in schools.

- If deemed unacceptable, document the contextual barriers and challenges discussed by stakeholders. 


\section{Methodology}

\section{STUDY DESIGN}

The study was a cross sectional descriptive study using qualitative approach to research. Purposive sampling methodology was employed to select the participants in this study. Information gathered under each method included the following:

- In-depth Interviews (IDIs): IDls focused on implementation issues and explored the views of parents, policymakers, education and health officials among others on the following broad areas: feasibility of expanding the current ASRH curriculum and delivery of school sex education using trained psychologists and acceptability of providing in-school reproductive health services by health workers.

- Focus Group Discussions (FGDs): FGDs explored teachers, adolescent and guardians' normative views on the following key broad areas: perceptions of SRH information and services received in school; SRH information and services delivery preferences and their views about the introduction of a comprehensive sex education programme. Identical discussion guides were used.

\section{STUDY AREA}

The study was conducted in Nima, a suburb of Accra in the Greater Accra region of Ghana. Nima is located in the Accra Metropolitan Assembly(AMA). The Accra Metropolitan Assembly has a total population of 1,665,086 representing 42 percent of the region's total population. Females constitute about $51.9 \%$ of the population whilst males are about $48.1 \%$ (GSS, 2013). The Metropolis is entirely urban (100\%). The metropolis has a fairly youthful population as about $42.6 \%$ of the population are children under 15 years with majority (47\%) of the populace being migrants, the highest in the Greater Accra region (GSS, 2014). Nima, the study site reflects the metropolitan structure as it serves as a hub for migrants. Early marriage is common practice in the area as three in ten $(36.3 \%)$ of the population aged 12 years and older are married in communities in this metropolis (GSS, 2014). As at July 2013, there were 14 Junior High Schools (JHS) in Nima with a total student population of 2,492 aged between 12-17 years (GES, 2013).

\section{STUDY POPULATION}

The study population included the following: Adolescents (both boys and girls) in JHS 1 to 3 (typically between the ages 12-17 years); GES and GHS officials; head teachers; teachers; and health services providers; parents/guardians of adolescents and other stakeholders such as the education experts at UNESCO, DFID, Ghana National Association of Teachers (GNAT), National Population Council (NPC) and the University of Ghana, Legon.

\section{Recruitment of students}

As at July 2013, there were 14 Junior High Schools (JHS) in Nima with a total student population of 2,492 between 12 and 17 years. The study team collaborated with the Accra Metro Education Office to select two (Nima Cluster of Schools and Al-Waleed JHS) out of the $14 \mathrm{JHS}$ based on two main 
criteria: recorded high school dropout rates due to teenage pregnancy and presence of trained ASRH teachers. From the two selected JHS, an estimated total of 79 adolescent students (39 females and 40 males) were recruited to participate in the study. Adolescent participants were further divided for discussion by sex and age: female students aged 12-14 years; female students aged 15-17 years; male students aged 12-14 years; and male students aged 15-17 years (Table 1).

A typical recruitment criterion used students who have not been absent from school over the term and students who have attended courses which included some SRH education. Informed consents were obtained from parents and an assent provided by the students before their participation in the study. Student participants provided assent and we also obtained parental consent to participate in the study. The FGDs typically held during the first week of vacation of the second term of the 2015/2016 academic year.

\section{Recruitment of parents}

This study recruited parents of students in the two schools to participate in discussions where the desired content of such information and services was to be explored. Parents of all students who met the selection criteria were eligible to participate in the study. However, precedence was given to parents who consented to participate and for instance, participate in school activities such as regular attendance of Parent Teacher Association (PTA) Meetings. Teachers, head teachers and the School Management Committee (SMC) chairman for the two schools assisted the research team in selecting and inviting parents for the discussions and interviews as well as in identifying private and secured locations for the discussions.

Table 1: Summary of Respondents in FGDS

\begin{tabular}{|l|l|l|}
\hline Participants & \multicolumn{2}{l|}{} \\
\hline Female Students & 2 & 19 \\
\hline $\mathbf{1 2 - 1 4}$ years & 2 & 20 \\
\hline $\mathbf{1 5 - 1 7}$ years & & \\
\hline Male Students & 2 & 20 \\
\hline $\mathbf{1 2 - 1 4}$ years & 2 & 20 \\
\hline $\mathbf{1 5 - 1 7}$ years & & \\
\hline Parents & 2 & 20 \\
\hline Males & 2 & 19 \\
\hline Females & & \\
\hline Teachers & 2 & 18 \\
\hline Mixed male/female groups & $\mathbf{1 4}$ & $\mathbf{1 3 6}$ \\
\hline Total & & \\
\hline
\end{tabular}

\section{Recruitment of other respondents:}

Purposively sampling was also used to select key informants to explore the views of policymakers, education and health officials regarding the acceptability and feasibility of the proposed interventions. At the national level, Ghana Education Service (GES) and Ghana Health Service (GHS) officers in charge of basic education, adolescent reproductive health, curriculum division and School Health Education Program (SHEP). At the district level, guidance and counseling officers, SHEP coordinators and sub district health directors, Head teachers, family planning providers and teachers. 
We also recruited designated officers/directors at UNESCO, NPC and GNAT in charge of adolescentrelated affairs and activities and clinical psychologists. Table 2 provides a summary of the various respondents in the key informant interviews.

Table 2: Summary of Key Informant Interview Participants

\begin{tabular}{|l|l|}
\hline Category of Respondent & Number interviewed \\
\hline Ghana Education Service Programme Managers & 5 \\
\hline Heads of Basic Educational Schools & 3 \\
\hline Ghana Health Service ASRH Programme Managers & 4 \\
\hline National Population Council SRH-Representative & 1 \\
\hline Members of Ghana Psychologist Association & 2 \\
\hline UNESCO Representative & 1 \\
\hline Teachers & 2 \\
\hline Total & $\mathbf{1 8}$ \\
\hline
\end{tabular}

\section{TRAINING OF RESEARCH ASSISTANTS AND PILOT STUDY}

All data collection instruments (IDIs, FGDs) were developed based on findings from existing and relevant research studies as well as a review of their recommendations. Questions are formulated bearing in mind the existing Ghanaian context with regards to sexuality education and ASRH. To determine and ensure cultural appropriateness, all instruments were pretested and refined accordingly before the commencement of the main study.

All research assistants received training on the purpose of the study, data collection tools interviewing skills and how to transcribe qualitative data. The training was facilitated by a consultant in this study who has expertise in qualitative studies. The training comprised of classroom work, mock interview session and field pilot. All the research assistants were university graduates with previous experience in qualitative data collection who were engaged by Population council for this study.

\section{DATA COLLECTION}

\section{In-depth interviews}

Semi-structured interview guides were developed and used for the data collection. The interview guide focused on implementation issues and explored the views of policymakers, education and health officials regarding the acceptability and feasibility of expanding the current ASRH curriculum and delivery of school sex education using trained psychologists as well as the acceptability and feasibility of providing in-school reproductive health services by health workers. Interviews were conducted in private and lasted approximately 45 minutes, covering the following areas: history of inschool ASRH; current ASRH topics and content; mode of delivery, successes and challenges with the current mode of delivery; viability of expanding the content of the current ASRH curriculum; practicability of and processes for delivering comprehensive school sex education using trained psychologists; viability and acceptability of providing in-school reproductive health services by health workers; recommendations for improving curriculum and mode of delivery. 


\section{Focus Group Discussions}

Semi-structured focus group discussions (FGDs) guides were designed to explore normative views of $\mathrm{SRH}$ information received while exploring the feasibility and acceptability of the proposed solutions. The guide explored adolescent and guardians' normative views on the following key broad areas: current ASRH topics covered and mode of delivery in school; participants' views on the introduction of a comprehensive sex education programme; SRH information and services delivery preferences; viability and acceptability of providing in-school reproductive health services by health workers; and the practicality of delivering sexuality education using psychologists at the school level. Identical discussion guides were used. Two research assistants conducted each FGDs, with one acting as a moderator while the second person took notes.

\section{ETHICAL CONSIDERATIONS}

The project proposal received ethical clearance from the Institutional Review Board (IRB) of the Population Council and also received approval from the GHS Ethical Review Committee (ERC).

\section{DATA MANAGEMENT AND ANALYSIS}

Data collected was managed and stored in the Population Council Ghana office. Interviews were conducted in private in a room and where feasible, interviewees were given a choice of being interviewed in English or Twi (prevalent local language). Audiotapes and notes were transcribed verbatim in English using Microsoft Word. A codebook was developed capturing various predetermined themes in the data collected and through the review of a portion of the transcripts. The codebook as nodes, and the data, was then imported into QSR Nvivo 11@ for analysis. The data sources (FGDs, and IDIs) were then classified and assigned classifications. Respondents were captured as cases and assigned specific attributes such as designation, sex and age. This enabled queries to be run in Nvivo to quantify the qualitative data sources and cases. Grounded theory was adopted for the analysis of the data. This approach involved three interrelated steps; open coding, axial coding and selective coding (Creswell, 2009). 


\section{Results}

\section{KNOWLEDGE ON ADOLESCENT SEXUAL AND REPRODUCTIVE HEALTH}

The results showed that adolescents had little understanding of adolescent sexual health. However, some respondents displayed familiarity with some components of sexual health such as abstaining from pre-marital sex, menstrual care, protection from pregnancy and issues regarding sexually transmitted infections. Educational managers also acknowledged the low level of knowledge of adolescents regarding sexual and reproductive health issues as illustrated by the quotes from respondents:

"Adolescent sexual health is like, it's a type of education given to an adolescent to keep his sensitive parts protected or how the person is, how the person should protect his or her sensitive parts" (16year female student, FGD)

"It [adolescent sexual health] is the act of growing from childhood to adulthood and without having sex at an early age or using protections like condoms and other pills" (16-year male student, FGD)

"...only a few of the school pupils have any knowledge about adolescent issues. Unless the students are staying with parents that are literates who are able to discuss such issues with their children but most of the time nothing, so if there can be a system of encouraging such knowledge and information in the school I think it will help the students" (Headmistress, IDI)

Knowledge of adolescents on reproductive health was equally low among the participants in this study. Nevertheless, some adolescents were able to identify what constituted adolescents reproductive health. Female student participants in this study were able to mention and describe some forms of reproductive health than their male counterparts as illustrated:

"Is a way of keeping the reproductive organ of the adolescent safe" (14 years female student, FGD)

"Adolescent reproductive health is the physical, mental and social wellbeing of the adolescent reproductive health" (15 years female student, FGD)

"It is the wellbeing of an adolescent child regardless of the situation (16-year female student, FGD)

Interviews with parents also showed that many parents did not also know what adolescent sexual and reproductive health was. Many parents believed adolescent sexual and reproductive health was mainly concerned with care during pregnancy and an adolescent learning hard in school. However, some parents were able to mention some aspects of adolescent sexual and reproductive health.

"My understanding of adolescent sexual health is that, a child is supposed to learn hard when he or she goes to school and how to take care of pregnancy" (24 years female guardian, FGD)

"If adolescent is supposed to have sex you should use a condom to protect their selves or may be take the pills to prevent them, to prevent the girl from teenage pregnancy ( $32 \mathrm{yr}$. male parent, FGD) "Is the emotional period, the stress, the tension that occurs during adolescent" (female parent, FGD) 


\section{RESPONDENTS' VIEWS ON PROVIDING SEXUAL AND REPRODUCTIVE HEALTH INFORMATION TO ADOLESCENTS}

The study showed that there was unanimity among respondents on the need to provide adolescents information on sexual and reproductive health. All participants believed adolescents require this information to enable them to live a healthy life and take good decisions. Participants acknowledged that in the absence of appropriate information provided to adolescents by someone with good knowledge on sexual and reproductive health, they are likely to rely on other sources to get this information. Stakeholders were of the opinion that some of these external sources may not be factual and this can affect the sexual and reproductive health choices of adolescents. The following quotes supports these assertions:

"It is important to provide our children with information on sexual and reproductive health because it would help them protect themselves. They will be able to avoid pregnancy, because you know that you can protect yourself with condom so you will not get pregnant when you have sex" (Male Parent, FGD)

"It is very important, sexual education I think is, is extremely important especially for students, errm I even think that it should even be added to the curriculum, it should be incorporated into their curriculum because as they grow, adolescent face a lot of problems especially their reproductive lifestyle so information on what to do and how to do certain things, are very important ok" (Clinical Psychologist-2, IDI)

Interviews with adolescents revealed that some of them could mention the importance of having access to information on sexual and reproductive health. Participants mentioned the importance of protecting one from unplanned pregnancies and preventing sexually transmitted infections as two benefits to having access to information on sexual and reproductive health. These were illustrated by the following quotes:

"It prevents us from getting diseases like HIV AIDS" (16-years Male student, FGD)

"When we have the information, it protects us from pregnancy and sexually transmitted infection" (17 years Female student, FGD)

\section{SOURCES OF INFORMATION ON REPRODUCTIVE HEALTH}

Five main sub-themes emerged as sources of information. These include; parents, teachers (school), electronic media (internet, television, radio) and peers. All respondents identified parents as key in providing sexual and reproductive health information. Respondents believed that parents, who are the first contacts to children, have a unique opportunity to provide them with the information that is required to inform healthy life choices. These views were held by the various stakeholders and emerged as unanimous position by all respondents. The following quotes illuminate these views:

"They (parents) tell us that we should stay away from any opposite sex, we should not have sex with any man and we should stay from bad friends, we should stay away from ehhhm bad behaviour, we should dress decently" (14-years female, FGD) 
"It is their parents who are supposed to teach them from their early age especially the females. But we here, Africans in particular, we don't do that. Only few of our parents use to do that" (38-years Parent, FGD)

"There is a saying that charity begins at home. So, I think the house must be where the education should come from before coming to the school. Because if the mother teaches you from the house and you come to the school and the teacher teach you, you get the understanding better than the only teacher will be teaching you" (27 years male parent, FGD)

"You know, education starts from the home, so when parents and guardians equip their children or wards with knowledge on adolescent reproductive health it will go a long way to make them informed because adolescent sexual and reproductive health is about our own biological system" (Education Manager 4, IDI)

However, it was observed that some parents are unable to play this role very well. Three reasons emerged as inhibiting factors to parents playing this role. The first reason was that some parents did not have knowledge and expertise to provide this information as it is deemed sensitive topic. Another impediment to this is lack of time as many parents are too busy. They therefore spend less time at home with their children. The final barrier mentioned in this study has to do with societal norms that prevent parents from providing adolescents with sexual and reproductive health information. These norms according to respondents have led to a perception that it was inappropriate for parents to discuss issues relating to sex with children. It was however noted that gradually this perception was changing and some parents especially the educated ones are now able to discuss sexual matters with their children as illustrated by some respondents in the study:

"...how will children get the information because when you go home in the morning, the parents are not at home, Mum has gone to the market and Dad has gone to the work so the child will have to get the information from other sources" (38-year male parent, FGD)

"Some of us the parents because of illiteracy, we do not know those [sexual and reproductive health] things ourselves. So, it is difficult to educate your child on something you don't know" (36-year female parent, FGD)

"I will say that because a lot of education has gone on the parents are now able to talk to their children. Hitherto, they thought that if they discussed sexual and reproductive health matters with their children they were rather encouraging them to engage in sexual activities early. So, they didn't tell them but hid it from them. Meanwhile, the child might have been hearing it elsewhere" (28-year female parent, FGD)

Another source of information on sexual and reproductive health were from teachers at schools. It was generally believed that teachers have an enormous role to play in this because adolescents spend more time in schools with their teachers. According to the study, these services are provided in schools through guidance and counseling. Another channel used to educate adolescents on sexual and reproductive health was the use of adolescent clubs in various schools. However, in IDIs with managers of educational institutions, it emerged that there were challenges with the current system as the coordinators of these programmes have other responsibilities such as teaching to perform. They are therefore unable to perform the additional task of coordinating sexual and reproductive health issues effectively as illustrated below: 
"....In all schools, we have girls' education facilitators, guidance and counselling coordinators and SHEP in school coordinators. But then they also have their work that they are doing at the end of the day, so it is a challenge" (Educational Manager 2, KII)

'In our girls' clubs, most of our topics are based on adolescent reproductive health, so, the NGOs also come to sponsor some of our programmes. When we organise children's forums most of our discussions are based on adolescent reproductive health. We show them pictures, show them about the consequences of pre-marital sex and then abortion" (Education Manager 1, IDI)

FGDs with adolescent also revealed that some form of education is often provided on sexual and reproductive health at schools. Adolescents in this study mentioned that they had received some sexual and reproductive health education from their teachers. The education covered areas such abstinence, and menstrual care as illustrated by following responses:

"We are told not to involve in premarital sex in school" (16-year female student, FGD)

"They [teachers] tell us about sex, they say sex is not good so we shouldn't have sex with our young girls and those sort of things" (16-year male student, FGD)

"We learn that when your menses start coming, you should keep yourself clean" (14-year female student, FGD)

"In some of the books, like Abrefi's first read letter day, you learn about menstrual cycle and also how to keep yourself during menses and food that you are supposed to eat and what you are not supposed to eat" (16 years female student, FGD)

It is however important to note that in discussions with students on the type of education provided to them in school by their teachers, sexual and reproductive health did not emerge spontaneously and were only mentioned after probing by interviewers.

The electronic media also emerged as one of the sources of sexual and reproductive health information for adolescents. Whereas most students mentioned radio, television and internet search engines such as google as common sources of information, parents expressed concern about the content of information that is often available through these channels. Respondents believed that this information would instead increase the risk of adolescents participating in promiscuous life styles. This was a major concern in both FGDs with male and female parents as illustrated by the following:

"On the television, the health talk shows, they tell the kind of food to eat to give you a healthy sexual reproduction" (16 years male student, FGD)

"Everyone listens to radio, where ever that you find yourself, whether you are in the car or in the house. A lot of the adolescents watch television, some adolescent are normally indoors they watch television a lot so when information on sexual and reproductive health is being delivered they listen to it" (Female Parent, FGD)

"I think the media especially the television is doing more harm than good. It is doing good as well but it is doing more harm than good. Since they have a lot of series that they show on television" (23-year male parent, FGD) 
"The media should stop bringing those bad sexual movies, they should stop bringing it on the television to help the children. When they bring it, some watch it and they do the practice so when they stop bringing it, it will reduce some irresponsible behaviors" (31-year female Parent, FGD)

Another source of information on sexual and reproductive was the learning from peers, relatives, churches and mosques. According to adolescents that participated in the study, during break and in the community when they meet with their peers they discuss wide range of issues including sexual and reproductive health matters. Some mosques and churches also provide education to adolescents on sexual and reproductive health as illustrated by quotes from some adolescents:

"We learn from friends in school and at home" (14-year female student, FGD)

"We learn from our friends, churches, mosque and relatives in the community" (16-year male student, FGD)

Despite the various sources of information on sexual and reproductive health, of the 79 adolescents who participated in the study, $27 \%$ selected school (teachers) as their most preferred source of information on SRH, followed by health workers $(25 \%)$ and parents $(21 \%)$. Other preferred sources included the internet $(6 \%)$, peers $(5 \%)$, media $(8 \%)$ and other sources such as churches, mosques and community members as $8 \%$ preferred these sources (Figure 1 ).

Figure 1: Adolescents Preferred Sources of SRH

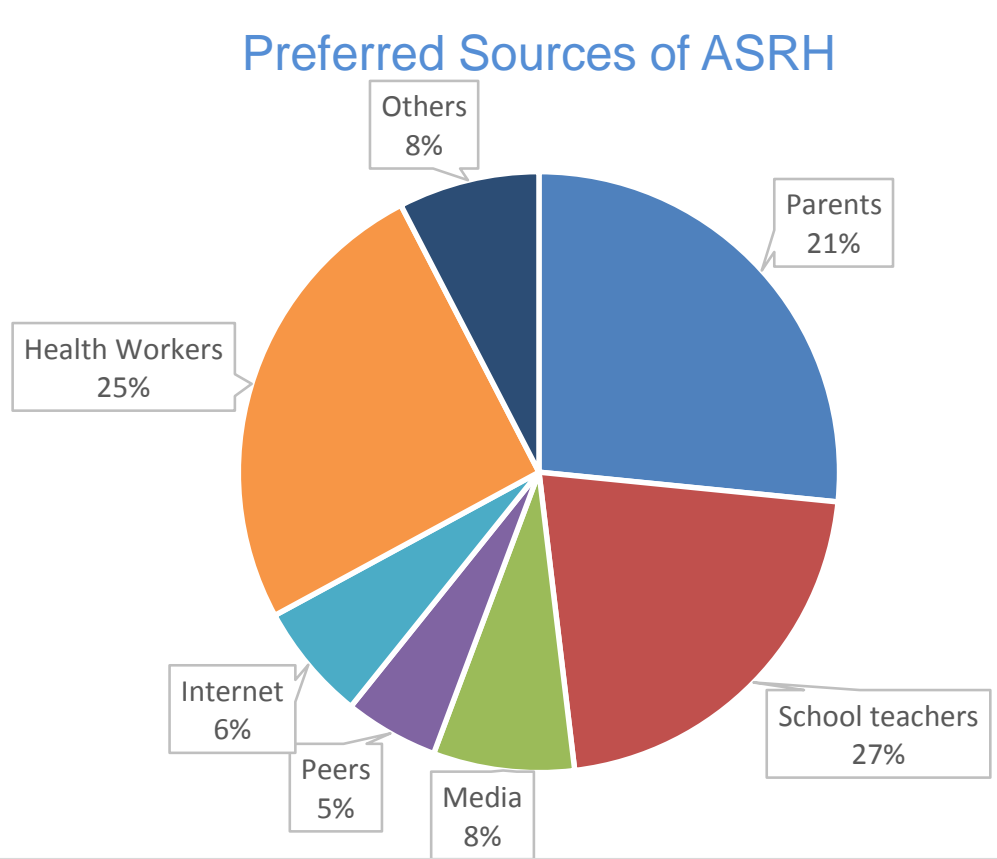




\section{PROVISION OF SEXUAL AND REPRODUCTIVE HEALTH INFORMATION AND SERVICES IN SCHOOLS}

There was unanimity on the need for school-based provision of adolescent sexual and reproductive health among all respondents in this study. This approach was viewed as the most appropriate way of addressing challenges that adolescent face in trying to access information and services regarding sexual and reproductive health. Participants believed that there has been an increase in enrolment in schools and many adolescents are now in school.

Thus, school-based channels will be the most appropriate platform to disseminate information on sexual and reproductive health. Another reason given by respondents that makes the school the most appropriate to deliver ASRH services was the long duration children stay at school. Respondents believed adolescents often spend more time in schools than any other environment and this makes this platform more appropriate for delivering these services. The following quotes buttress these points by respondents:

"The most important place is school and at home. Because for especially these Christians you go to churches on Saturdays or Sundays. Isn't it? Once a week. But school, at least 5 days in a week, so it the best place for educating adolescents on sexual and reproductive health issues" (38-year married male parent, FGD)

"I think, first of all I think the statistics now shows that most of our young people are in school so if you want to meet adolescents with information then you might as well go to where they can be found where most of them are. And if most of them are found in school as the statistics are telling us then it means that comprehensive sexuality education should start with the schools" (Representative, Adolescent Health, GHS, IDI)

"I also think that reproductive health services must be provided in schools. Children are exposed to a lot of information than we think. Many of them on the internet to seek information on certain things and the information they get may not be correct so I think when the schools provide reproductive services in the schools, they will be informed on behavioural changes" (Education Manager-2, KII)

"Ministry of Health, Ministry of Education and then Social Workers should put their heads together designed a professional syllabus to cater for adolescent reproductive health which will then be implemented by GES" (Headmaster, IDI)

Parents, education managers and health workers all agreed that there was a need to extend the sexual and reproductive health services in schools and there were little variations in views across the various respondents. Out of the 18 key informants interviewed, 15 supported school-based ASRH services. In FGDs among teachers, 14 of the 18 participants also supported this strategy of providing ASRH service. In FGDs with parents, 16 of 19 female parents and 14 of 20 male parent support this idea as illustrated on Figure 2. 
Figure 2: Respondents views on school-based ASRH

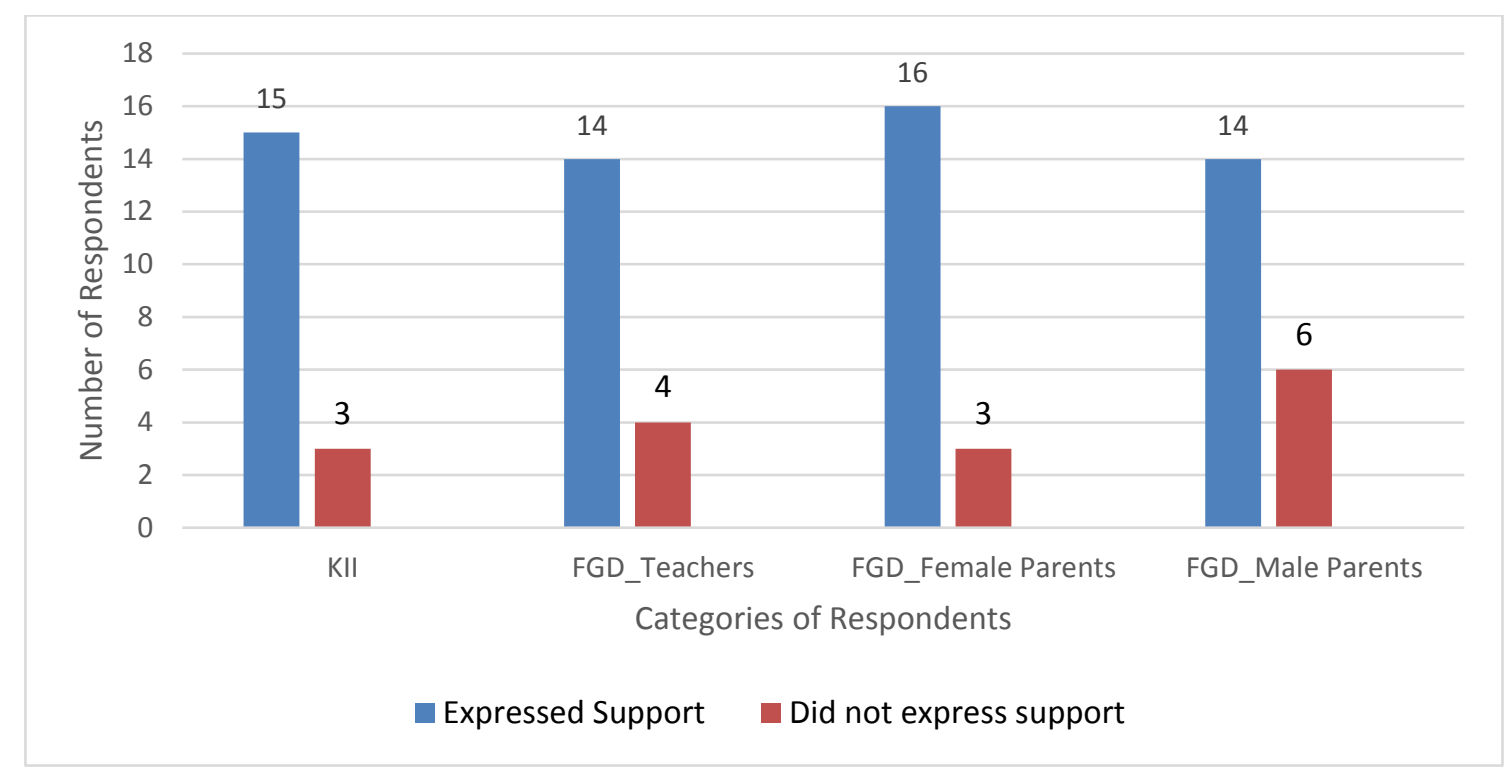

\section{VIEWS ON RANGE OF SERVICES TO BE PROVIDED IN SCHOOLS}

Respondents in this study mentioned some of the sexual and reproductive health service they deemed essential for inclusion in a school health programme as health education to students, counseling services, and the provision of sanitary pads. These services were believed to be essential in ensuring that adolescents live a good and healthy life. However, mixed views were express on the distribution of condoms to students. Some respondents felt that it was appropriate to distribute condoms to students (adolescents) as some adolescents often engage in unprotected sex. Therefore, the provision of condoms will prevent them from contracting STIs, becoming pregnant or impregnating someone. However, some respondents were of the view that distributing condoms could amount to promoting sexual activity among adolescents' as they will try to "experiment" with the use of condom. Generally, parents and teachers were against distributing condoms as part of sexual and reproductive health service to be provided in schools was unpopular (Figure 3). The following quotes from respondent illustrate these points:

"....But in our schools, we provide the counselling services, we can have the health corner alright where counselling services are provided, where materials are provided for reading, where we could have the sanitary towels or pads and other things. But for now, I won't subscribe to having condoms in school because of our socio-cultural background" (Education Manger 4, KII)

"The condoms should not be given to students, they should just teach them because some bad students may do it after school, they may go somewhere else, and so if these pills and these condoms are introduced to the students and people who have already done it, they will say oh since there is medicine and there is condom we can do it every time and always so it should not be given to them at all" (Female Parent, FGD)

"To me if they provide these services such as health education, distributing sanitary pad and condoms in school it is a good idea because nowadays if you advise the young ones not to have sex, they will have it. So, it should be provided in schools for them to protect themselves" (Male Parent, FGD) 
"Sharing condoms in the school might lead the children to go and do, go and try to have sex because if you share the condom to them they will ask you what are they going to use it for? It is not balloon" (24-year Male Guardian)

Figure 3: Respondents view on types of service to include in school-based ASRH

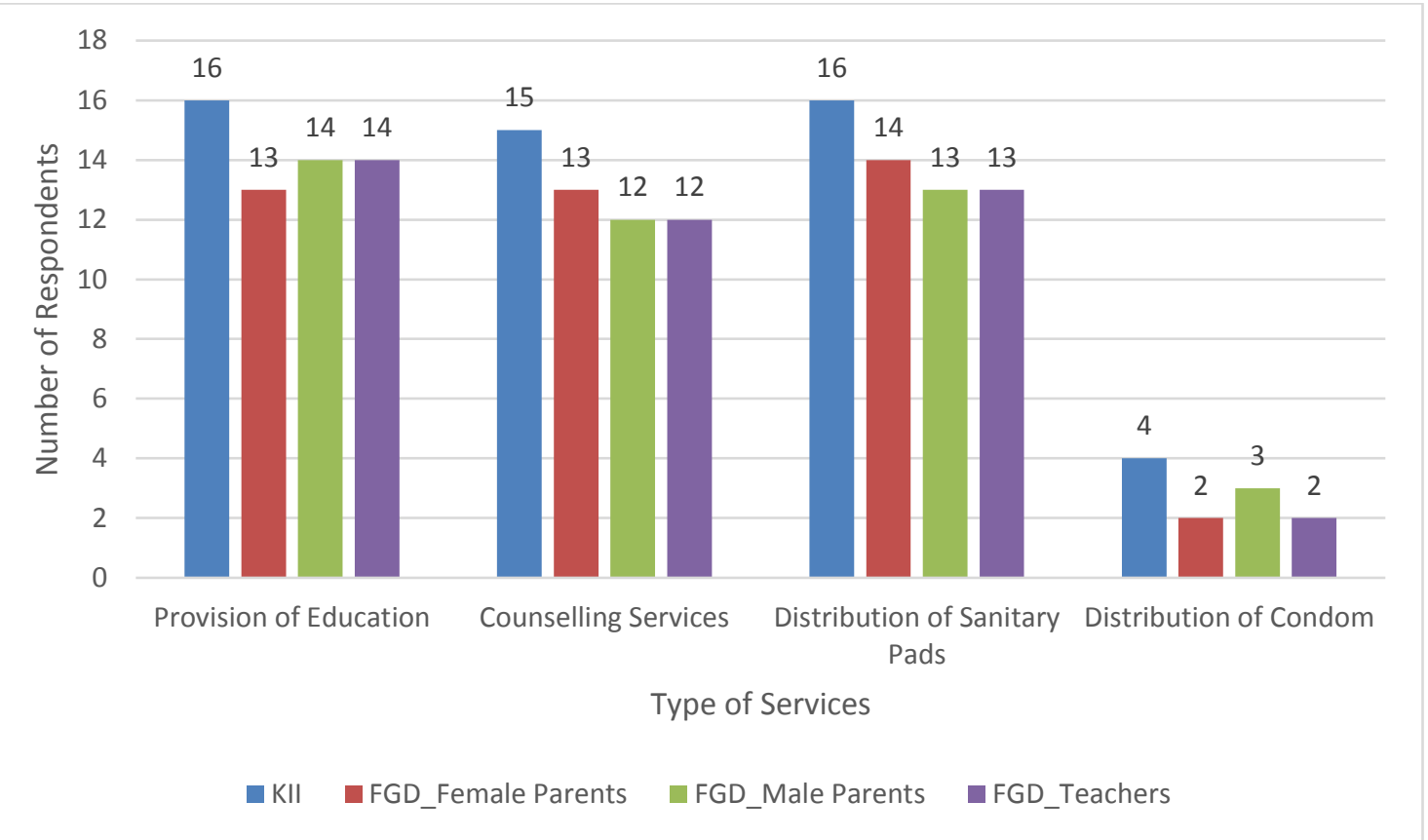

Though respondents felt that it was inappropriate to distribute condoms in school, they believed that it might be possible to do some consultation and possible revision of policy as the current educational policy on sexual and reproductive health does not permit distributing condoms to student within a school premise as illustrated:

"My brother I told you from the very onset that for now Ghana Education Service doesn't permit the provision of condoms in our schools. Do you get the point...in our schools we don't allow the provision of condoms, they don't give condoms to the children in the school but however just as I said and I reiterate, if you have any condoms to provide let it be community-based" (Education Manager 6, IDI)

\section{PERCEIVED BENEFITS OF PROVIDING SCHOOL-BASED SEXUAL AND REPRODUCTIVE HEALTH}

Respondents in the study believed that the provision of adolescent sexual and reproductive health in school will help adolescents make good sexual and reproductive health choices and reduce unplanned pregnancies and sexually transmitted infections among adolescents. Access to the information and services will also reduce dropout rate especially among females who are often compelled to drop out of school because of unplanned pregnancies. Enhanced school-based sexual and reproductive health was therefore perceived as a good step in trying to make these services accessible to adolescents.

"With the services, it will go a long way for instance to it will reduce the rate or abortion and teenage pregnancy" (Education Manager-1, KII) 
"My view is they should provide sexual health services in schools, it is a world known issue now that we are having girls getting pregnant in schools but if these services had provided them I don't think they will find themselves in these situations" (Education Manager 2, KII)

"... it will also help them to delay a pregnancy, get pregnant when they want to, reduce the incidence of STI's and of course all these things will help them to improve their ability to stay in school and also improve their economic status in future" (Education Manager 3, KII)

\section{POTENTIAL CHALLENGES IN INTRODUCING COMPREHENSIVE SCHOOL-BASED ASRH}

The study showed that there might be challenges in attempt to introduce sexual and reproductive health services in schools. Respondents identified resistance from faith-based schools and parents as some of the challenges since some of the services are perceived as inappropriate for adolescents. Provision of contraceptives in schools emerged as one such area that may likely meet resistance from both school authorities and parents. However, respondents were of the view that if extensive consultation is done to clarify the type of services that would be provided, it may receive the endorsement of all stakeholders including managers of faith-based schools.

"You see some churches will rise up against it. You know Catholics they are against the use of contraceptives and the rest, let alone providing the services at school" (Education Manager 1, IDI)

"Yes, first is resistance from schools and from teachers... we need to do a lot of some form of advocacy and some orientation for them to look at the benefits of such information before we rush into the school" (Education Manager 3, IDI)

"The only problem we'll have is our conservative nature as Ghanaians. That's the only challenge because, for instance, how will the parents feel if the child comes home to tell the mother that they shared condoms for us in school? or they are doing family planning in schools. Every parent will be alarmed. So that's the challenge; the society's response to some of the services that we will give to the young people" (Health Manager, GHS, IDI)

\section{AVAILABILITY OF CURRICULUM ON POP/FLE AND VIEWS ON ENHANCE CURRICULUM ON POP/FLE}

The study revealed there was no separate curriculum on population and family life education at the basic, junior and senior high school in Ghana. However, various aspects of issues on population and family life education were embedded in courses such as religious and moral education, integrated science and social studies at various levels. For example, in social studies, there were topics on the family and its functions, roles and responsibilities of parents and children. Nonetheless, these did not comprehensively cover areas of population and family issues. The following response illustrate these point:

"We do not have curriculum on population and family life education but we have aspects in social studies where we teach them about the family, the composition of the family, the functions of the family, the roles and responsibilities of parents then rights of the parents and of the children, then 
adolescent reproductive education also comes in for them to know about their body, changes in the body, things that occur as they are growing" (Education Manager-2, IDI)

"There is no curriculum on this area. We only have aspects of it in different subjects such as social studies, religion and moral education and science" (Education Manager 3, IDI)

Nevertheless, stakeholders in this study believed developing a curriculum for population and family life education was essential to bring together the various aspects that are scattered in different subjects. To achieve this, key stakeholders will have to be brought together to discuss about the content of the curriculum on Population and Family Life Education that will be acceptable by all stakeholders and implemented in schools in Ghana.

"In Ghana, we have it [POP/FLE] in some subjects, it's not a subject on its own, so to me it must be a subject on its own" (Education Manager-2, IDI)

"They can bring experts around, sit down, look at the current content and then see how best they can improve, make it more holistic, more practical, and devote more time, give it more ample time on the time table" (Education Manager-1, IDI)

"We have to do stakeholders engagement at that level, we need to engage all the political stakeholders, education and the community, traditional rulers to ensure they appreciate the importance of these because some of these things.... Those are the areas we need to engage and build consensus in other to improve the curriculum" (Education Manager 3, IDI)

Despite the fact that stakeholders perceived the need for enhanced curriculum on POP/FLE, they believed that developing another curriculum for a course is going to increase the number of courses at the basic and Junior High School level which are already many. To circumvent this challenge, educational stakeholders believed the curriculum could be developed and taught but the subject should not be examinable as illustrated by the following quotes:

"The course is already many and introducing another course is going to add the burden of subjects the students are supposed to learn and write exam on...but it could be made a non-examinable subject" (Education Manager 4, IDI)

"It should be like a subject but not examinable like Life Skills, Music and Dance and other subjects (Education Manager 1, IDI)

\section{CHANGES REQUIRED TO EFFECTIVELY IMPLEMENT POP/FLE}

The study showed that not much changes are required to develop a curriculum on POP/FLE since there is no separate curriculum in existence. Once key stakeholders agree to develop a curriculum, then the process could begin. However, a review of aspects of POP/FLE found in other subjects could be done to consolidate that into a new curriculum. After which areas not currently covered in any curriculum could be added. This process according to educational managers will require bringing together various stakeholders to develop the curriculum, which can then be shared among stakeholders to make an input. Stakeholders could also be brought together to deliberate on the content of such a curriculum to make it an all-inclusive document right from the beginning. Another 
change proposed was for schools to set up adolescent corners to integrate the POP/FLE with the enhanced ASRH services that will also be provided by health experts as illustrate by respondents:

"We mentioned the agencies that collaborate to work together and I think experts can meet to re-look at what is the ground now and see what they can add to it and then produce a material to cover all the details" (Education Manager 1, IDI)

"The processes are; 1 , these stake holders coming together to look at the content, adding to the content. 2, Ministry of Education and all these agencies should be given the material produced from all those collaborators who met and then the curriculum division of ministry of education re-looks at it to produce a material from it" (Education Manager 3, IDI)

"...My suggestion is that it should be part of the curriculum. Then number two, educational directorates should set up adolescent reproductive centres, it can be in clusters" (Education Manager2, IDI)

\section{USE OF PSYCHOLOGISTS TO PROVIDE ADOLESCENT SEXUAL AND REPRODUCTIVE EDUCATION}

The study showed that many adolescents did not know exactly who a psychologist was but believed a psychologist was trained to take care of people with mental disorder or in what some refer to as someone who "reads people's mind". Nevertheless, some students were able to identify a psychologist as someone trained to understand individual human behaviour as illustrated

"A person who is trained to come out with the ability to know whether something is wrong with human or the behaviour" ( 16 years male student, FGD)

Regarding using psychologists to provide school-based sexual and reproductive health services to adolescents, the results of the study showed mixed views but with more people supporting the use of psychologists. Whereas some respondents believed it was the best way to address lack of access to information and services on ASRH, other respondents were of the view that health workers and trained teachers were better placed to provide these services than a psychologist. To those who believed it was appropriate to have trained psychologist, this was required to enable teachers to focus on their primary responsibility of teaching. To them even though the current education system allows for the training of teachers to serve as guidance and counseling officers at school, these teachers are not able to play their roles very well. This is because they are supposed to combine that role with regular teaching, which render them ineffective. The study participants observed that some students do not feel comfortable discussing sexual and reproductive health issues with their teachers as they may be perceived by their teachers as "spoilt" children. Therefore, bringing a neutral person such as a psychologist was the best way to go. It was also mentioned that psychologists were better placed to detect students who are going through emotional challenges and other psychological problems to offer them the needed support and counseling in a timely manner in order to prevent them from worsening. The following quotes illustrates these views from respondents:

"They (psychologists) will also serve as role models to them in the first place. Because these students, most often when they have resource persons come in from outside, they tend to appreciate 
them more. They, seeing them as the work they do, they will tend to learn from them a lot" (FGD, Teachers)

"....A child may have some problem at home and that may manifest in inappropriate sexual behaviour and we need such people to be able to delve into the details and be able to provide appropriate counselling for such kids" (Education Manager 3, KII)

"I think it will be a great advantage for them coming in because they will add to whatever teachers are being given. Because these kids we have they are very complicated and sometimes when teachers are saying what they know, they will say oh you are supposed to come and teach me science, you are supposed to come and teach me Mathematics, how do you think that you know about sex or you know about the changes that occur to me" (Male Teacher, IDI)

"It will help them know as an adolescent since we are not taught at home when we enter into that stage. Our parents don't have time or maybe they don't feel comfortable teaching us certain things and in the schools too, the teachers may not be able to teach us everything but if we have the psychologists or when we have this expert in the school based on the education and the counselling it can help reduce these teenage pregnancies it will send information around [about] this STIs" (Health Worker, Adolescent Corner, IDI)

"Several, quite apart from providing the information, if it so happens that some children have some challenges, you know, there will be the opportunity to intervene with any of the psychotherapy.... So, it will be more like, yes providing the information but also giving an added advantage of providing some therapeutic care if indeed there is the need for that to be done" (Clinical Psychologist-1, IDI)

Contrary to the view that psychologists should be assigned to offer sexual and reproductive health education to students, some respondents believed that it is not a feasible approach to addressing sexual and reproductive health challenges among adolescents.

"Training psychologists to visit schools is not sustainable. You just have to train the teachers to be able to do what the psychologist is supposed to do because if you're going to train psychologists and dispatch them to the schools, it has to do with making sure you're facilitating their movement. And I don't know if the government will be in the position to absorb them. So just use available structures, we have guidance and counseling coordinators there and what GHS does is that we train the guidance and counseling coordinators in adolescent sexual and reproductive health." (Health Manager, Adolescent Health, GHS)

"Ehhh, we have to strengthen our counselling department, we have, GES has counselling department and those departments should be strengthened, more psychologists and counsellors would have to be trained, well equipped with an in-depth knowledge in adolescent reproductive health so that we could refer students to that department for a redress" (Headmaster, IDI)

The study also showed that to operationalize any school-based provision of sexual and reproductive health education and services, gender-related issues should be considered in deciding who offers education on ASRH. In FGDs with teachers, parents and students, it emerged that it would be preferable for male service provider to be assigned to male students whilst females are assigned to female students. According to respondents, this will make students feel comfortable to discuss sexual and reproductive health issues. It was also observed in the study that when providing sexual and 
reproductive health education, it would be important to separate males from female students or on religious or cultural appropriateness as illustrated below:

"For our Islamic religion, what we are supposed to do is we have the females, we don't mix the females and the males. So, we have to have a psychologist for the female and the psychologist for the male" (FGD, 46-years Teachers)

"Sometimes my peers, sometimes I feel comfortable in, of telling my peers my problems than like an elderly person. In case my peer knows about that problem, the person will gladly like to tell me the answer" (16 years female students, FGD)

"Madam like, they should separate the boys from the girls so that people can ask questions. When they are mixed, people feel shy to ask some questions which ermm is bothering them. So, when they separate the boys from the girls, people will be able to ask questions and will be given a solution to all their problems" (15-years female student, FGD)

Female students were more concerned about separating male and female students. For female students, male students often make fun of them when female reproductive and sexual organs are mentioned. In addition, female students believed that female teachers and service providers have experienced what they may be experiencing and are therefore in better position to explain and provide support to them. The following quotes illustrate these points:

"A female teacher, because she is a woman and she has been what you are going through now. And she will more have knowledge of teaching" (17 years female student, FGD)

"...the boys they like when the teacher is teaching and will be saying, they will be saying vagina and those things about females. The boys will be happy and they will be laughing" (16 years female student, FGD)

Despite a few dissenting views on the use of psychologists to provide school-based ASRH, majority of the participants across categories believed that it was feasible and acceptable in the Ghanaian context. Out of the 18 key informants interviewed, 16 perceived the use of trained psychologist as feasible and acceptable. In FGDs with female parents, 13 out of the 15 female parents who responded to this question also believed it was feasible whilst 12 out of the 16-male parent who answered this question were of the view that it was feasible and acceptable. Among teachers, 12 out of the 16 also believed it was feasible and acceptable to use psychologists to deliver ASRH services in schools (Figure 3). Respondents who were opposed to the use of psychologists generally raised concerns about the availability of trained psychologists and how to remunerate them for their services as illustrated:

"And also knowing the number of schools in Ghana and the number of psychologists that will be in the system, I think eh visiting a school or sometimes they might not be able to visit the school in that case it would not be effective" (Female Teacher, FGD)

"The idea [use of psychologist] is good but the problem will be placement and who to employ them and pay for their services. You know psychologist come with some level of high education and the money to pay them will be the problem" (Male Teacher, FGD) 
Figure 1: Respondents view on feasibility and acceptability of using trained psychologist to provide school-based enhanced ASRH

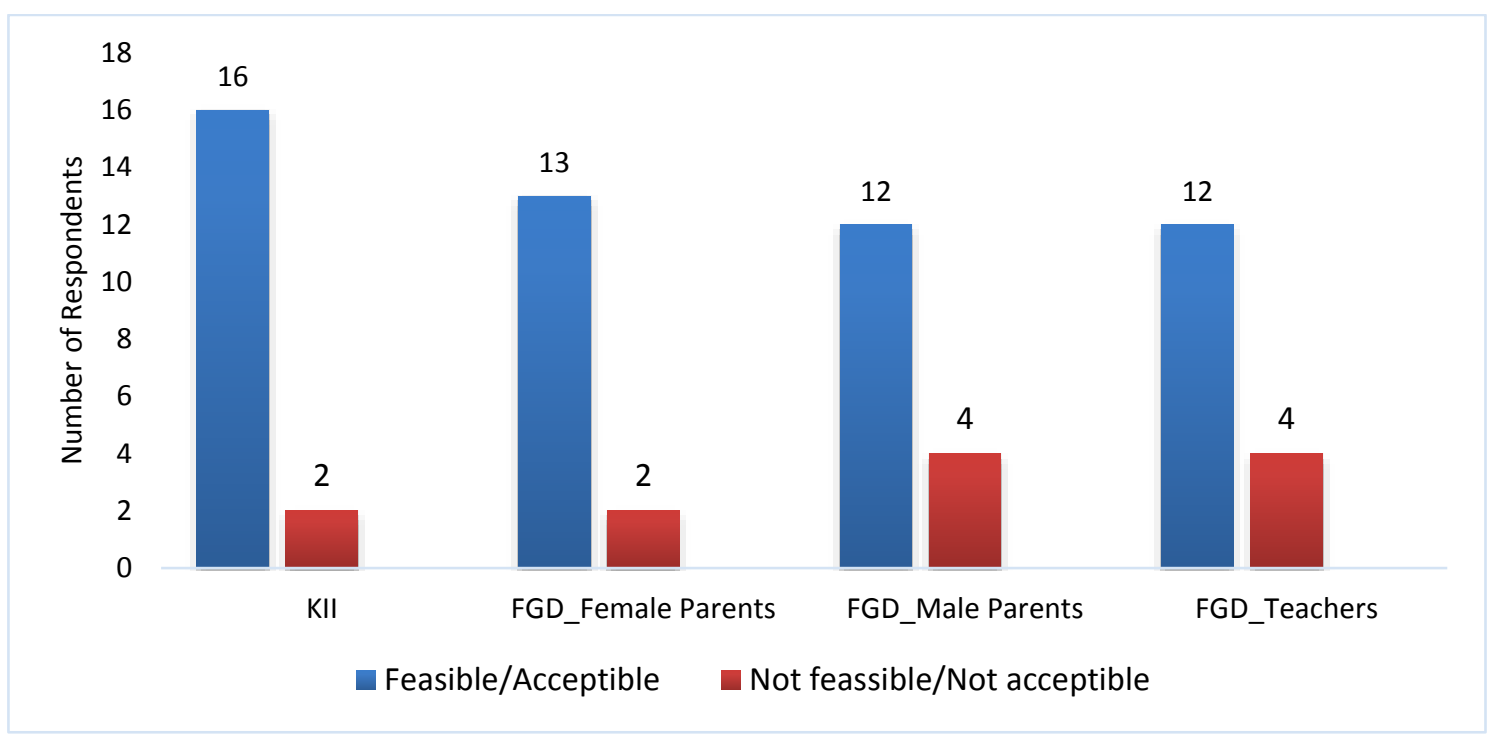

The results of the study also showed that to be able to implement such a system it will involve a deal of work with the existing bureaucracies and good collaboration with various stakeholders including ministry of education, Ghana education service, Ghana Health Service and Development Partners who are currently engaged in sexual and reproductive health services and education in order to minimize anticipated challenges.

"As I said if you do not use the right channels the heads may not allow because they may think you are interrupting their contact hours and those would be the challenges. They will not be ready to give you access to the people so if you use the right channels I don't think you will have any problem" (Headmistress, IDI)

"This is policy issue and will require bringing all stakeholders together to discuss. If Ghana Education Service makes it a policy, then nobody can say no to it. We will implement it" (Teacher, IDI)

The study further found that one approach that could be used to implement school-based adolescent sexual and reproductive health is to put schools in clusters where psychologists can be assigned to a cluster of schools. This was important because it was envisioned that it may be difficult to find enough trained psychologists to be assigned to each school as illustrated:

"What can be done is to group schools, a number of schools or students that can meet at a centre that trained psychologist can meet with about two hundred, three hundred, five hundred students in a big hall giving the same information at the same time so by that the target groups can be met, I mean the number of children that he can meet will expand and will be more" (Education Manager 2, KII)

"Psychologists, how many are in the system? We may have to put schools together where you assign one psychologist in-charge" (Education Manager 4, KII) 


\section{USE OF HEALTH WORKERS TO PROVIDE SCHOOL-BASED EDUCATION AND SERVICES ON SEXUAL AND REPRODUCTIVE HEALTH}

The results of the study also showed that stakeholders had a positive view on the use of health workers to deliver sexual and reproductive health services in schools for adolescents. This, according to respondents will ensure that adolescents have access to the information on sexuality as well access to reproductive health services. Using health workers was also perceived as a strategy that could be used to link school-health services to the mainstream health care system for easy referral. Generally, the results did not show difference in respondents' view on the psychologists and health workers as they were believed to be well equipped to handle sexual and reproductive issues better. Out of the 18 key informants interviewed, 16 perceived the use of health workers as feasible and acceptable. In FGDs with female parents, 13 out of the 15 female parents also believed it was feasible whilst 12 out of the 16 male parents were of the view that it was feasible and acceptable. Among teachers, 12 out of the 16 also considered it was feasible and acceptable to use health workers to deliver ASRH services in schools (Figure 5).

Yes, I agree that health workers should visit schools to talk to the children about sexual and reproductive health. It will help them very well because the health workers can easily refer a student with a problem to hospital to get quick care" (Female Parent, FGD)

"You know that is the work of health workers. They have been trained and they have knowledge on sexual and reproductive health. So, it would good to use them" (Male Parent, FGD)

"When we have this adolescent health centre with the expert going there to work is very easy, for instance we have Nima, see Nima Cluster of schools for instance if we can establish one there, another cluster of school, Dansoman" (Education Manager-1, IDI)

Figure 2: Respondents view on feasibility and acceptability of using health workers to provide school-based enhanced ASRH

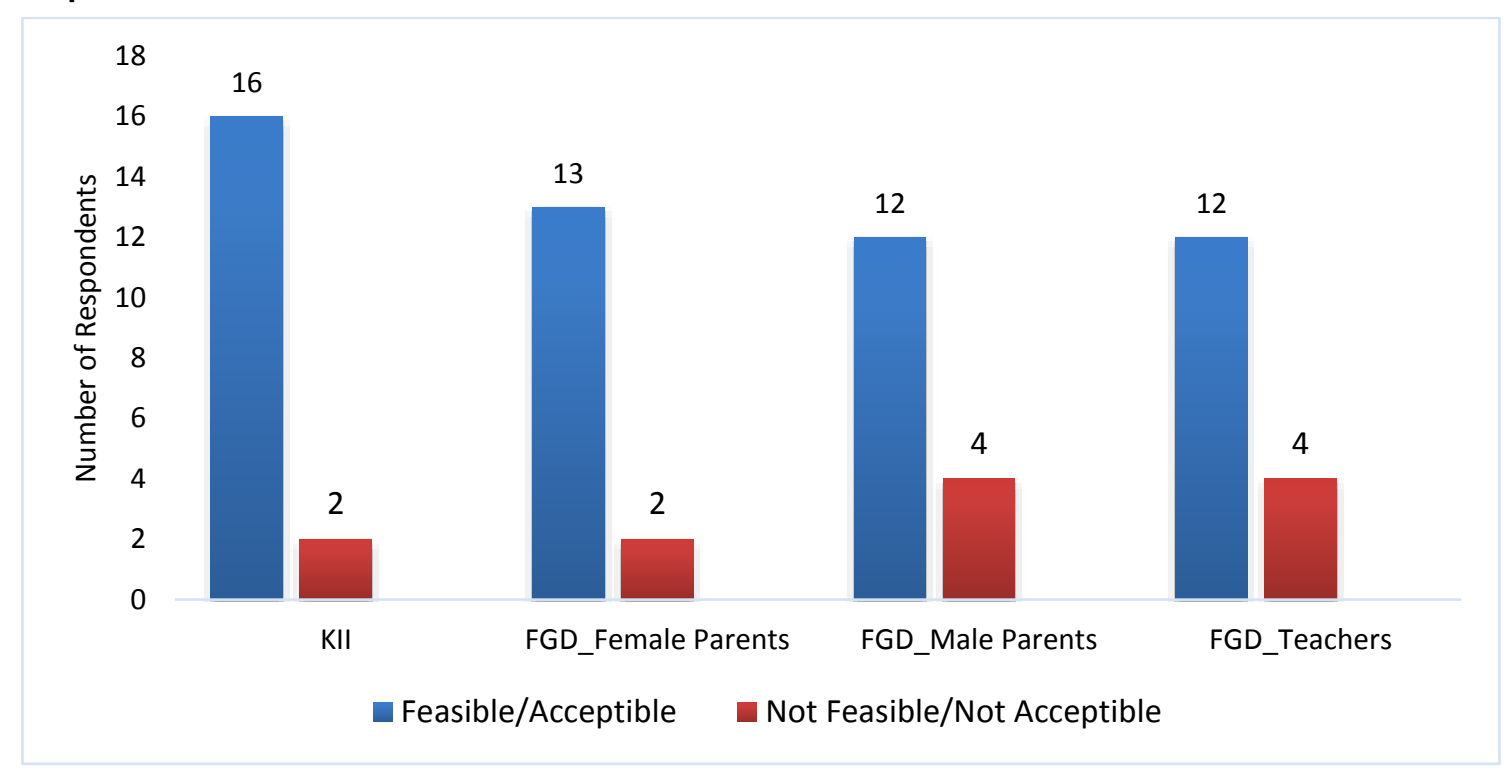




\section{CHALLENGES AND CHANGES REQUIRED TO IMPLEMENT SCHOOL-BASED EDUCATION AND SERVICES ON SEXUAL AND REPRODUCTIVE HEALTH}

Stakeholders were of the view that the use of trained psychologists and health workers for the provision of adolescent and sexual reproductive health will require making changes on school timetables to cater for the time that would be used to provide such services. Another challenge that needs to be addressed is to identify an appropriate service points or rooms where such services would be provided as privacy is required to assure adolescents that information provided would be treated as confidential. To be able to implement this system of school-based provision of sexual and reproductive health services, will also require changes in existing policy and acquiring logistics that would be used in the delivery of the service.

"It will not be easy because sometimes the school will tell you they already have the time table for the term. So maybe giving you that enough time they [school] will not agree" (Health Worker-1, IDI)

"....You would have to start from the policy level come to the management and then it transcends to the school level. So, the challenge is that you must have the materials that you would use for the education ready, err if you have any teaching and learning materials all these should be ready and it should be down to earth to reach the target group" (Education Manager-6, KII)

"There should be a space or a room for them. So maybe there wouldn't be availability of a place for them to work. And then maybe we need to train more of the health personnel because this require extra training to deal with this thing. There should be [an] adolescent nurse, a nurse who... a guru, somebody who knows adolescent health, who has been trained, had extra training on adolescent health to tackle them. So maybe shortage of staff will not allow us to err... reach our goal" (Health worker-2, IDI) 


\section{Discussion}

\section{KNOWLEDGE ON SEXUAL AND REPRODUCTIVE HEALTH}

The study showed that adolescent did not have comprehensive knowledge on sexual and reproductive health issues. However, comprehensive knowledge on sexual and reproductive health is important in determining the reproductive health choices they make; some of the choices may lead to untoward outcomes on their lives as well as their generations. It has been found in longitudinal study that children that are born from such unplanned pregnancy by adolescents also have a higher likelihood of experiencing similar faith in future, that is female children born from unplanned pregnancy are more likely to become adolescent mothers in future whilst their sons have a significant probability of incarceration as adults (Walker \& Navarro Paniagua, 2012). The findings of this study support an earlier study among adolescents in Ghana which found low knowledge on female menstrual cycle and fertility period (Awusabo-asare, Biddlecom, Kumi-Kyereme, \& Patterson, 2006).

\section{SOURCES OF INFORMATION ON SEXUAL AND REPRODUCTIVE HEALTH}

The study showed that adolescent received information on sexual and reproductive health from five main sources: parents, school, electronic media and their peers. Majority of respondents believed that parent had an important role to play in the provision of information on sexual and reproductive health. However, the extent to which this role was executed remain unknown as many respondents believed that given the sensitive nature of issues relating to sexual and reproductive health and societal norms, it may be difficult for some parents to perform this role effectively. A study among adolescents in Central Region of Ghana by Owusu, Blankson \& Abane (2011) showed that the major sources of information on sexual and reproductive health available to adolescents were their friends $(30 \%)$, radio/television (26\%) and parents (13\%) (Owusu et al., 2011). However, this study found that the most common sources of information on ASRH was the school and health workers contrary to where they get their information.

\section{ACCEPTABILITY OF SCHOOL-BASED SEXUAL AND REPRODUCTIVE HEALTH SERVICES}

The study showed that stakeholders perceived the provision of sexual and reproductive health services in schools as laudable and implementable idea. When adolescents receive the right information from experts on sexual and reproductive health, they are empowered to make right decision on their sexual life. This therefore has the potential of reducing the negative effects on unsafe sexual practices with their associated consequences. A study among adolescents in the United States showed that adolescents who received comprehensive sex education in school were significantly less likely to report teen pregnancy than those who received no formal sex education (Kohler, Manhart, \& Lafferty, 2008). In India, it was found that the introduction of sexual and reproductive intervention in school resulted in a significant increase in the knowledge in both boys and girls (Nair et al., 2012). 
Stakeholders in this study believed that school-based ASRH services could include: distributing sanitary pads to females to cater for their menstrual needs, educating adolescents on all aspects of sexual and reproductive health. However, providing contraceptive services including condoms were believed to have the potential to rather promote promiscuous lifestyle among adolescents. Nonetheless, a study in USA on school-based ASRH showed that educating adolescents on abstinence only was found not to reduce the likelihood of unplanned pregnancy (Kohler et al., 2008). Drawing from the findings of this study in the USA, it would be important for any discussions on designing a plan for school-based sexual and reproductive services to go beyond promoting abstinence only to making it possible for adolescents to access services that can ensure that sexually active adolescents engage in safe and protected sex.

\section{CHANGES REQUIRED TO IMPLEMENT SCHOOL-BASED ASRH SERVICES}

Though stakeholders in this study thought it was acceptable and feasibility to introduce school-based ASRH; its implementation will require consultations to determine areas to cover and type of services to provide. When community and parents embrace this strategy, its implementation will be easier and has the potential to achieve the merited impact. Programmes that promote access to and uptake of adolescent sexual and reproductive health services are reported to be most effective when adolescent-friendly facility-based approaches are combined with community acceptance and demandgeneration activities (Denno, Hoopes, \& Chandra-Mouli, 2015). In South Africa for example, a pilot study on school-based sexual and reproductive health services was found to be acceptable in the community and feasible with scale-up (Frohlich et al., 2014). Ghana can draw from this experience to pilot this system in selected institutions where lessons learnt can then inform scaled up. The implementation of school-based ASRH services also required changes on the school timetables to make room for such services. Furthermore, it was necessary to identify a place in the school where these services would be provided.

\section{USE OF PSYCHOLOGISTS AND HEALTH WORKERS FOR DELIVERING SEXUAL AND REPRODUCTIVE HEALTH SERVICES}

The study showed that majority of the respondents perceived a system that will make it possible for sexual and reproductive health services to be delivered in schools by trained psychologists as essential as the present system do not meet the needs of adolescents. Teachers who are in-charge of guidance and counseling services perform those roles in addition to their primary teaching role and less attention is placed on this additional task. The study also showed that some adolescents may not be comfortable discussing sexual issues with their teachers, as they may be perceived to be immoral. Therefore, using neutral people such as a psychologist who visit the school to provide such services will increase participation and interest. Psychologists were also viewed to be better placed to detect emotional distress and offer timely counseling.

It is well documented that adolescents who exhibited delinquent behaviours, use alcohol and marijuana are more likely than their counterparts who do not practice these vices to engage in vaginal sex without using a condom (Thompson \& Auslander, 2011). These behaviours have psychological undertones in which case teachers and parents may not be well resourced to handle. However, health workers and psychologists are well trained and resourced to detect such behaviour and provide 
support. A study in Massachusetts showed that using a school nurse to deliver intervention aiming at encouraging adolescents to stop smoking was effective as intervention condition participants were almost twice as likely to be abstinent per self-report at 3 months compared with control participants (Pbert et al., 2011). Using school nurse to provide contraceptive service was also found to have positive as it increased access (Gabzdyl, 2010).

\section{THE PARADIGM OF ASRH INFORMATION PROVISION IN SCHOOLS}

The study showed that existing sources of information on ASRH such as parents, teachers, peers, electronic media, community members, churches and mosques had practical challenges. Social norms especially made it difficult for parents and teacher to freely provide these services. The existing guidance and counseling services in school which serves as channels for providing education and support on sexual and reproductive health were being undermined by competing roles as the counselors had to still perform the primary role as teachers. To that end, respondents generally believed these existing systems were not achieving their objective, which requires a restructuring of the services to make it more comprehensive. The study reported that students were not particularly aware of who psychologists were and what they do but believed they are trained to "read peoples' mind and take care of people with mental illness.

Stakeholders however felt that it might be good for both trained psychologists and health workers to provide school-based sexual and reproductive health to adolescents. However, stakeholders perceived a number of practical challenges around how this could be implemented. Key among the challenges was how to pay for the services that health workers and trained psychologists will render, and availability of psychologists to cater for all schools. Another important challenge raised was acceptability of certain services such as distributing condoms and provision of contraceptives services especially in faith-based schools. Nonetheless, respondents believed that garnering enough support from parents and other stakeholders could make this acceptable. In designing the systems of using trained psychologists and health workers to provide ASRH services, attention must be paid to genderrelated stratification to make it possible for male professionals to provide services to male students whilst female professionals are also in-charge of services to female students. The use of health workers and trained psychologists will not only provide access to sexual and reproductive health services but also help in identifying and addressing other psychosocial problems. It would also be helpful in creating a link between the school health service and formal health system deliver to foster referral as diagrammatically presented in figure 6 . 


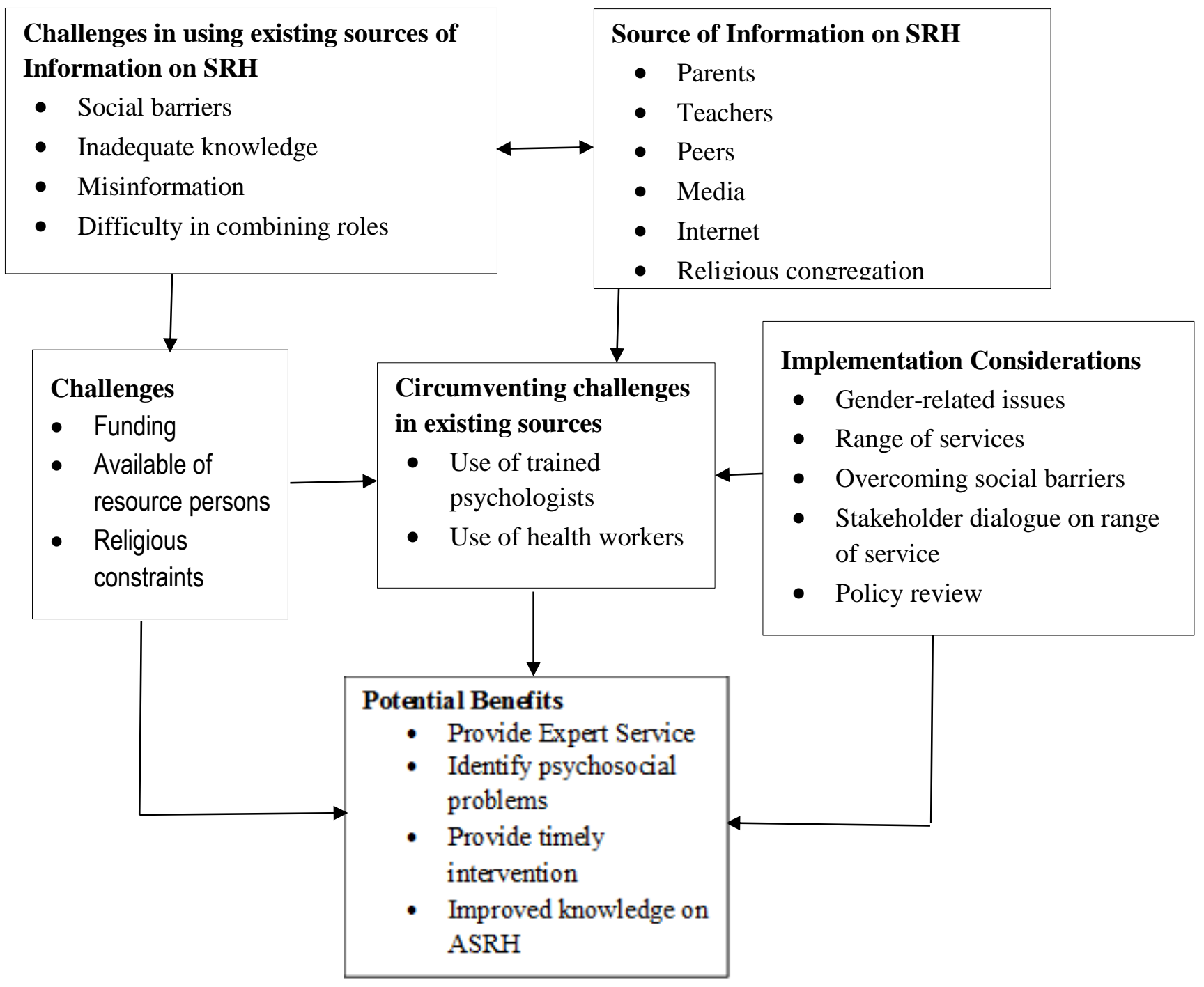

Figure 3: Frame work on use of trained psychologist and health workers in providing school-based ASRH Services

\section{FEASIBILITY AND ACCEPTABILITY OF ENHANCED CURRICULUM FOR POPULATION AND FAMILY LIFE EDUCATION}

The study generally showed that there was no curriculum that comprehensively addressed issues concerning POP/FLE in Ghana. There were however, smaller aspects of this scattered in other subject areas, which were not comprehensive and well structured. Respondents were of the view that increasing enrolments in school implies many adolescents were now in school, therefore a welldeveloped curriculum on POP/FLE will make the delivery of this information reach a large number of adolescents. The introduction of subject on POP/FLE also has the potential to break social barriers that prevent discussing sexual and reproductive health issues in public. 
In school, the interaction between the teacher and students take the form of organized block of lessons and where there is curriculum covering critical areas in POP/FLE, the teacher can adopt participatory methods of teaching to impart valuable skills to their students, such as negotiation, listening, communication, refusal and taking informed choices or decision about their sexual lives. As noted by the World Health Organization, when schools do not address family life, reproductive health, and population issues, they miss an opportunity to positively affect students' education, quality of life and relationships, and ultimately the economy and productivity of nations (WHO/UNICEF/EDC, 2008).

Stakeholders in this study were of the view that a stakeholder's dialogue could be organized to deliberate on the content of a curriculum. It would also require a review of existing subjects where some aspects of POP/FLE to consolidate the pieces from different subject into one curriculum. Since there is no existing curriculum on POP/FLE, respondents were unable to make recommendations on changes required but believed engaging stakeholders could lead to their inputs where after drafting the curriculum; this could be given to experts for review and dissemination before adoption as shown in figure 7.

Figure 4: Framework for POP/FLE

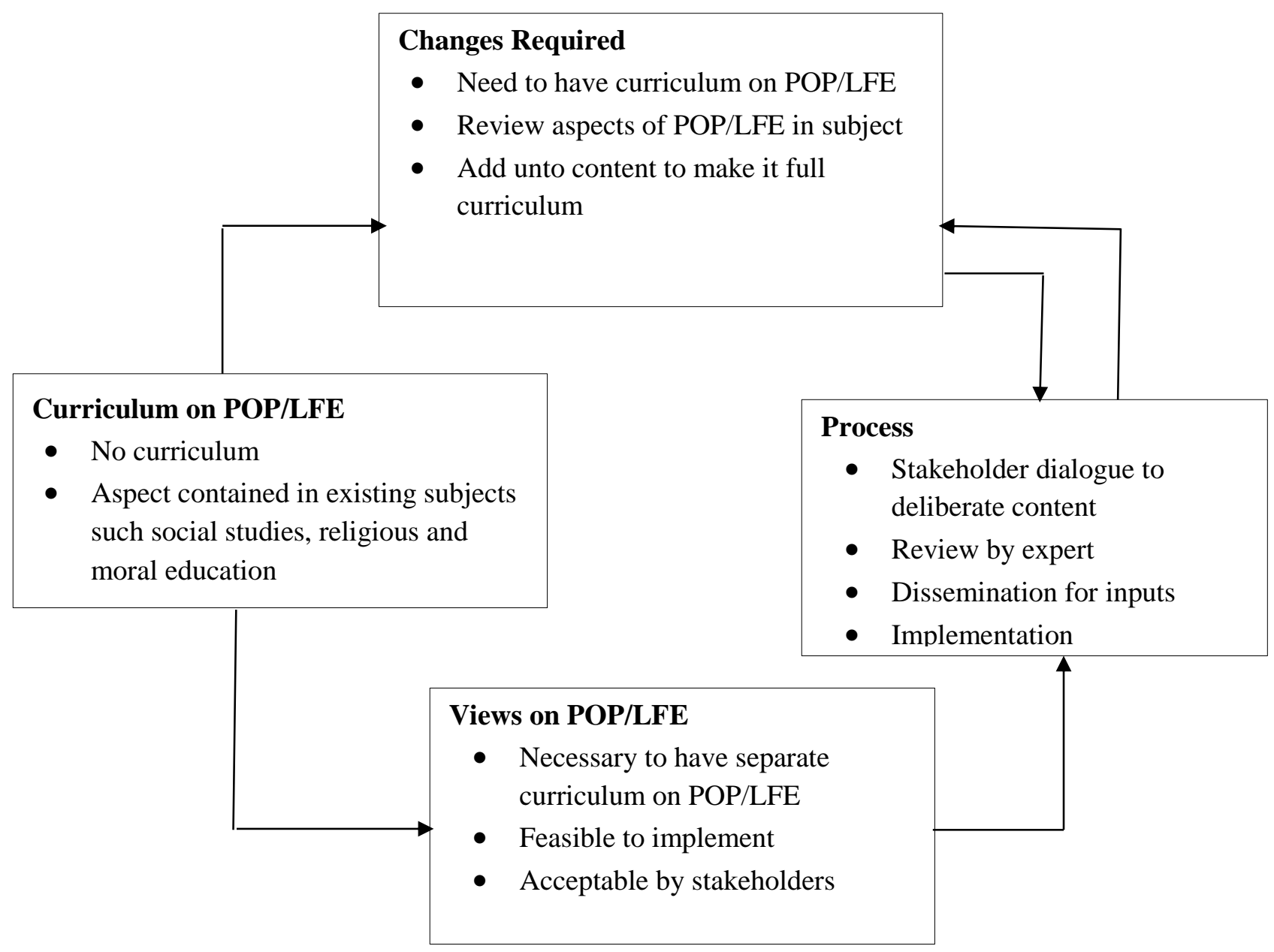




\section{Conclusion}

The study concludes that stakeholders generally believed there was the need for an enhanced adolescents sexual and reproductive health services in school as the present system of delivering these services were not sufficiently addressing the ASRH needs. The use of trained psychologists and health workers were perceived as feasible and acceptable in the Ghanaian context to meet the sexual and reproductive health needs of adolescents provided provisions are made to cater for the financial and other logistical considerations in its implementation. In addition, there were no existing separate curriculum on POP/LFE at the basic and Junior High Schools. Stakeholders believed it was important to consider a curriculum to address the POP/LFE needs of adolescents. Therefore, developing a separate curriculum for POP/LFE was also perceived to be feasible and acceptable among stakeholders in the study. However, comprehensive stakeholder engagement was required to determine content and implementation strategies.

\section{Dissemination of Results and Publication Policy}

During the preparatory stage of the study, relevant stakeholders who were engaged in the study's development process were mapped to ensure that the study created ownership and sustainability within the government agencies. Key stakeholders such as GES and GHS staff as well as nongovernmental organizations and governmental agencies such as National Population Council were contacted to make their input and the research design aligned to meet stakeholder needs.

An initial presentation of the study will be made to GES, GHS and other key stakeholders such as non-governmental organizations and governmental agencies such as National Population Council to seek their contributions to and support of the study to ensure that the processes are well understood and owned as well as ensure research uptake by the government agencies. Briefing of key officials in the ministry will also be done. The research team will also look for meetings and conferences which relevant decision-makers will be attending and to make presentations. The United Nations Educational, Scientific and Cultural Organization's (UNESCO) office in Ghana will be engaged during the exploratory stages of the study and their experience and recommendations from previous inschool ASRH activities will be brought to bear on the implementation of the follow-on intervention process. The research team will prepare and share a project brief on the study process and outcomes which will be presented at different key meetings and conferences on ASRH and School Health Education to facilitate discussion on piloting the proposed solutions to determine their effectiveness with the goal of informing a review of the current in-school ASRH programme. The project brief will also be disseminated through the STEP-UP channels to inform the wider research community.

Preliminary results will be presented to the GES and GHS for their input, comments and suggestions before a revised presentation is made to a wider segment of stakeholders, including key officials in the relevant ministries and stakeholders. The research team will make presentations at key meetings and conferences on ASRH and School Health Education which relevant decision and policy-makers, with the goal of informing a review of the current in-school ASRH program. The final project report will be shared with all key stakeholders and disseminated through the STEP-UP channels. Final reports of the study will be produced and disseminated by the GES, GHS and Population Council at regional and international meetings with the ultimate goals of influencing SRH educational programming globally. We anticipate publishing in at least one peer-review journal for the wider scientific community. 


\section{Project Management}

Placide Tapsoba (MD, MPH), the Country Director of Population Council's Ghana office coordinated the study and provided administrative leadership and technical support.

Mr Terence Adda-Balinia (MA) was the Principal Investigator who coordinated the research design and implementation of the project including analysis and synthesis of the results and other day-to-day activities for the study.

Dela Kusi-Appouh (PhD), Staff Associate and Gertrude N. Nyaaba (Msc), Programme Officer in the Ghana office provided technical support to the Principal Investigator in designing and implementing this study to ensure adherence to agree upon technical and administrative obligations and supervised the analysis and interpretation of study findings.

Research Assistants (RAs): RAs were master's degree holders with relevant experience in collecting data. Preference were given to RAs who have prior experience working on Population Council Ghana research studies. Prior to this study, we had a three-day training to explain the study to RAs, train them on research ethics, data collection tools and pretest questionnaires to ensure compliance. 


\section{References}

Awusabo-asare, K., Biddlecom, A., Kumi-Kyereme, A., \& Patterson, K. (2006). Adolescent Sexual and Reproductive Health in Ghana : Results from the 2004 National Survey of Adolescents. Occasional Reeport No 22. New York.

Ayalew, M., Mengistie, B., \& Semahegn, A. (2014). Adolescent-parent communication on sexual and reproductive health issues among high school students in Dire Dawa, Eastern Ethiopia: a cross sectional study. Reproductive Health, 11(1), 77.

Braeken, D., \& Cardinal, M. (2008). Comprehensive Sexuality Education as a Means of Promoting Sexual Health. International Journal of Sexual Health, 20(1-2), 50-62.

doi:10.1080/19317610802157051

Coley, R., Votruba-Drzal, E., \& Schindler, H. (2009). Fathers' and mothers' parenting practices and responding to adolescent sexual risk behaviors. Child Development, 80(3), 808-827.

Creswell, J. W. (2009). Research design: Qualitative, quantitative, and mixed methods approaches. Research Design Qualitative Quantitative and Mixed Methods Approaches, 3rd, 260. doi:10.1016/j.math.2010.09.003

Crockett, L. J., Raffaelli, M., \& Moilanen, K. L. (2003). Adolescent sexuality: Behavior and meaning. Faculty Publications, Department of Psychology, 245.

Denno, D. M., Hoopes, A. J., \& Chandra-Mouli, V. (2015). Effective strategies to provide adolescent sexual and reproductive health services and to increase demand and community support. Journal of Adolescent Health. doi:10.1016/j.jadohealth.2014.09.012

Frohlich, J. a, Mkhize, N., Dellar, R. C., Mahlase, G., Montague, C. T., \& Abdool Karim, Q. (2014). Meeting the sexual and reproductive health needs of high-school students in South Africa: experiences from rural KwaZulu-Natal. South African Medical Journal = Suid-Afrikaanse Tydskrif Vir Geneeskunde, 104(10), 687-90. doi:10.7196/SAMJ.7841

Gabzdyl, E. M. (2010). Contraceptive care of adolescents: overview, tips, strategies, and implications for school nurses. The Journal Of School Nursing: The Official Publication Of The National Association Of School Nurses, 26(4), 267-277. doi:10.1177/1059840510374459

GES. (2013). Ghana Education Service Report for Accra Metropolitan Assembly. Acrra.

GSS. (2013). Ghana 2010 Population and housing census: National analytical report. Accra-Ghana. Retrieved from http://www.statsghana.gov.gh/

GSS. (2014). 2010 Population and Housing Census: District Analytic Report for Accra Metropolitan Area. Accra. Retrieved from http://www.statsghana.gov.gh/docfiles/2010_District_Report/Greater Accra/AMA.pdf

Harden, A., Brunton, G., Fletcher, A., \& Oakley, A. (2009). Teenage pregnancy and social disadvantage: systematic review integrating controlled trials and qualitative studies. BMJ (Clinical Research Ed.), 339(7731), b4254. doi:10.1136/bmj.b4254 
Idele, P., Gillespie, a, Porth, T., Suzuki, C., Mahy, M., Kasedde, S., \& Luo, C. (2014). Epidemiology of HIV and AIDS among adolescents: Current status, inequities, and data gaps. Journal of Acquired Immune Deficiency Syndromes, 66(SUPPL. 2), S144-S153. doi:10.1097/QAI.0000000000000176

International Planned Parenthood Federation. (2009). From evidence to action: Advocating for comprehensive sexuality education. Reproductive Health, 32 .

Kabiru, C., Izugbara, C., \& Beguy, D. (2013). The health and wellbeing of young people in subSaharan Africa: an under-researched area? BMC International Health and Human Rights, 13(1), 11.

Kincaida, C., Jones, D. J., Sterrettb, E., \& McKeec, L. (2012). A review of parenting and adolescent sexual behavior: The moderating role of gender. Clin Psychol Rev, 32(3), 177-188.

doi:10.1016/j.cpr.2012.01.002.A

Kohler, P. K., Manhart, L. E., \& Lafferty, W. E. (2008). Abstinence-Only and Comprehensive Sex Education and the Initiation of Sexual Activity and Teen Pregnancy. Journal of Adolescent Health, 42(4), 344-351. doi:10.1016/j.jadohealth.2007.08.026

McCave, E. L. (2007). Comprehensive sexuality education vs. abstinence-only sexuality education: The need for evidence-based research and practice. School Social Work Journal, 32(1), 14-28.

Minnick, D. J., \& Shandler, L. (2012). Changing Adolescent Perceptions on Teenage pregnancy. Children \& Schools, 33(4), 241-248. doi:10.1159/000326706

Nair, M. K. C., Paul, M. K., Leena, M. L., Thankachi, Y., George, B., Russell, P. S., \& Vijayan Pillai, H. (2012). Effectiveness of a reproductive sexual health education package among school going adolescents. In Indian Journal of Pediatrics (Vol. 79). doi:10.1007/s12098-011-0433-x

Owusu, S. A., Blankson, E. J., \& Abane, A. M. (2011). Sexual and Reproductive Health Education among Dressmakers and Hairdressers in the Assin South District of Ghana. Afr J Reprod Health, 15(4), 109-119.

Pbert, L., Druker, S., DiFranza, J. R., Gorak, D., Reed, G., Magner, R., ... Osganian, S. (2011).

Effectiveness of a school nurse-delivered smoking-cessation intervention for adolescents. Pediatrics, 128(5), 926-36. doi:10.1542/peds.2011-0520

Thompson, R. G., \& Auslander, W. F. (2011). Substance use and mental health problems as predictors of HIV sexual risk behaviors among adolescents in foster care. Health \& Social Work, 36(1), 33-43.

UNESCO. (2009). Internatioanal Technical Guidance on Sexuality Education: An evidence-informed approach for Schools, Teachers and Health Educators. Paris: UNESCO.

Walker, I., \& Navarro Paniagua, M. (2012). The Impact of Teenage Motherhood on the The Impact of Teenage Motherhood on the Education and Fertility of their Children: Evidence for Europe. Bonn.

WHO/UNICEF/EDC. (2008). Family Life, Reproductive Health, and Population Education: Key Elements of a Health-Promoting School. Geneva.

World Bank. (2015). Data: Sub-Saharan Africa (developing only). Washington, DC. 


\section{Appendices}

\section{Appendix 1 FGD Adolescent Information sheet and assent forms}

\section{INFORMATION SHEET}

ii. Title of Study: Acceptability and feasibility of introducing strengthened school-based sexual and reproductive health information and services in Accra, Ghana

iii. Introduction: You are invited to take part in a research study. Before you decide whether to participate, please allow me to explain why the research is being done and what it would involve. Please take the time to read or to listen as I read the following information. Please stop me at any time to ask questions if there is anything that is not clear, or if you would like more information. When all of your questions have been answered and you feel that you understand this study, you will be asked if you wish to participate in the study or not. If yes, you will be asked to sign this Informed Assent form. You will be given a signed copy to keep. Please keep the information you hear in the group confidential. Your parent or guardian has already given permission. However, you do not have to say yes. We have talked to your parent or guardian and he/she agrees that you do not have to say yes. This study is being conducted under the leadership of the following people:

Name: Terence Adda-Balinia

(Principal Investigator in Ghana)

Program Officer,

Population Council Ghana

Box CT 4906, Cantonments

Tel: $+233302780711 / 2$

Email:taddabalinia@popcouncil.org
Name: Dr. Tapsoba L. Placide

\section{(Co-investigator for the study)}

Country Director

Population Council Ghana

Box CT 4906, Cantonments

+233302 780711/2

ptabsoba@popcouncil.org

Population Council Ghana conducts this study) under the STEP UP (Strengthening Evidence for Programming on Unintended Pregnancy) Research Programme Consortium which generates policy-relevant research to promote an evidence-informed approach for improving access to sexual and reproductive health services.

iv. Nature of research: We are conducting social research on adolescent sexual and reproductive health programming in Ghana. The purpose of the study is to find out your perceptions about the usefulness of the current sexuality education in schools and your views about the introduction of comprehensive sexuality education in schools.

Comprehensive sexuality education includes enhancing the content of the existing life skills/POP/FLE education and strengthening the delivery of SRH information and services in schools. You have been invited to take part because you are an adolescent who lives in this community and is currently receiving education in one of the target schools. 


\section{v. Participants involvement:}

- Duration /what is involved: If you agree to take part in the study, we will ask you to sign this form. You will be asked also to respond to questions on you and/or another adolescent's reproductive health (access to and content of reproductive health care) experience in this community. This will take about an hour of your time. We may contact you again if we need to follow-up on issues discussed with your child or an official from Population Council might visit to verify your informed consent.

- Potential Risks: An inconvenience may be the time and effort you take to be a participant. You may find one or more questions that we ask to be discomforting, emotionally sensitive or upsetting. You do not have to respond to any question that makes you uncomfortable. You may end the focus group at any time without penalty or loss of any benefits to which you are entitled. A risk may be a breach of confidentiality (something you say that is accidentally provided to others), but we will take precautions to see that this does not happen.

- Benefits: There are no direct benefits to you or your child for participating in the study. You may find an indirect benefit in knowing your child has participated in an important study that could help others like him/her in Ghana.

- Compensation/Payment: No compensation will be given for participation in the study, but we will provide a little snack (a drink and a pack of food) will be made available to you after the discussion

- Confidentiality: The information that is collected during the interview will be kept private. No one will be told that you have participated in the study. Other focus group participants will know what you say during the focus group discussion. However, we will ask participants to keep information shared during the focus group confidential. The information that is collected during the focus group and the other interviews will be used to design an adolescent reproductive health program for adolescents in Ghana. The study team will make every effort to protect your privacy and maintain the confidentiality of all the information that you provide. Your name or other identifiers will not be included in any published documents from this study. Data will be stored in a computer dedicated to this study that only the study team can access. We will not share any of your information with your parents. All audio-recorded interviews will be handled only by the research team and stored at Population Council Ghana for a period of five years after which all recordings will be destroyed.

- Voluntary participation/withdrawal: Your participation in this study is completely up to you. If you decide not to participate, you will not lose any existing benefits to which you are entitled. If you agree to participate in this study, you may end your participation at any time without penalty or loss of existing benefits to which you are entitled. If you decide to take part, you are free to skip any questions. You are free to withdraw at any time without affecting your relationship with the study team, your school or health service providers.

- Outcome and Feedback: The results of the study will be used to design an adolescent reproductive health program for adolescents in Ghana and will also be presented at conferences and published in journals.

- Funding information: Population Council Ghana conducts this study in collaboration with funding from the UK Government (Department for International Development) under the Step-Up study. 
- Who has reviewed the study for ethical issues? This study has been reviewed by Population Council IRB and the Ghana Health Service Ethical Review Committee. Who to Contact for Clarification: If you have a concern about any aspect of the study, you should ask to speak to the researchers who will do their best to answer your questions. You may also call Terence Adda-Balinia Program Officer, Population Council, Accra, Ghana at Tel: $+233302780711 / 2$, Mob: +233 244843790, email:

taddabalinia@popcouncil.org. or Ms. Hannah Frimpong, Administrator, Ghana Health Service Ethical Review Committee, Research and Development Division, Ghana Health Service, P. O. Box MB190, Accra at Mobile 2330243235225 / 2330507041223 email: hannah.frimpong@ghsmail.org 


\section{CONSENT FORM/INFORMED ASSENT FOR ADOLESCENT FGD PARTICIPANTS (12 YEARS+)}

\section{PARTICIPANT STATEMENT AND SIGNATURE}

I certify that I voluntarily agree to take part in this FGD discussion, that the study has been explained to me. All my questions have been answered satisfactorily. I understand I am free to discontinue participation at any time if I so choose.

Signature or thumbprint of Participant

(Thumbprint for those who cannot read and write)

Date

\section{INVESTIGATOR STATEMENT AND SIGNATURE}

I certify that the participant has been given ample time to read and learn about the study. All questions and clarifications raised by the participant have been addressed.

Signature of person who sought consent

Date 


\section{Appendix 2 Parent permission Information sheet and consent forms}

\section{INFORMATION SHEET}

ii. Title of Study: Acceptability and feasibility of introducing strengthened schoolbased sexual and reproductive health information and services in Accra, Ghana

iii. Introduction: You are invited to take part in a research study. Before you decide whether to participate, you need to understand why the research is being done and what it would involve. Please take the time to read or to listen as I read the following information. You may talk to others about the study if you wish. Please ask me if there is anything that is not clear, or if you would like more information. When all of your questions have been answered and you feel that you understand this study, you will be asked if you wish to participate in the study, and if yes to sign an Informed Consent form. You will be given a signed copy to keep. This study is being conducted under the leadership of the following people:

Name: Terence Adda-Balinia

(Principal Investigator in Ghana)

Program Officer,

Population Council Ghana

Box CT 4906, Cantonments

Tel: +233 $302780711 / 2$

Email: taddabalinia@popcouncil.org
Name: Dr. Tapsoba L. Placide

(Co-investigator for the study)

Country Director

Population Council Ghana

Box CT 4906, Cantonments

+233302780711/2

ptabsoba@popcouncil.org

Population Council Ghana conducts this study) under the STEP UP (Strengthening Evidence for Programming on Unintended Pregnancy) Research Programme Consortium which generates policy-relevant research to promote an evidence-informed approach for improving access to sexual and reproductive health services.

iv. Nature of research: We are conducting social research on adolescent sexual and reproductive health programming in Ghana. The purpose of the study is to find out perceptions of adolescents about the usefulness of the current sexuality education in schools and their views about the introduction of comprehensive sexuality education in schools. Comprehensive sexuality education includes enhancing the content of the existing life skills/POP/FLE education and strengthening the delivery of SRH information and services in schools. Your child/ward has been invited to take part because s/he is an adolescent who lives in this community and is currently receiving education in one of the target schools in Nima.

\section{v. Participants involvement:}

- Duration /what is involved: If you agree to let your ward take part in the study, we will ask you to sign this form. Your ward will be asked to participate in a group discussion to discuss his/her opinions about usefulness of the current sexuality education in schools and his/her views about the introduction of 
comprehensive sexuality education in schools. The group discussions will take at least an hour. We may contact you again if we need to follow-up on issues discussed with your child or an official from Population Council might visit to verify your informed consent.

- Potential Risks: An inconvenience may be the time and effort your child takes to be a participant. Your child may find one or more questions that we ask to be discomforting, emotionally sensitive or upsetting. Your child does not have to respond to any question that makes him/her uncomfortable. Your child may end the interview at any time without penalty. A risk may be a breach of confidentiality (something that your child will say that is accidentally provided to others), but we will take precautions to see that this does not happen.

- Benefits: There are no direct benefits to you or your child for participating in the study. You may find an indirect benefit in knowing your child has participated in an important study that could help others like him/her in Ghana.

- Compensation/Payment: No compensation will be given for participation in the study, but we will provide a little snack (a drink and a pack of food) will be made available to adolescents after the discussion

- Confidentiality: The information that is collected during the interview will be kept private. No one will be told that your child has participated in the study. The study team will make every effort to protect your child's privacy and maintain the confidentiality of all that he/she provides. Your child's name or other identifiers will not be included in published documents from this study. All the information that is collected during this study will be audio-recorded and treated in confidence. We will ask participants to keep information shared during the focus group confidential but will avoid asking questions that are likely to lead to overly personal disclosures in those groups. All audio-recorded interviews will be handled only by the research team and stored at Population Council Ghana for a period of five years after which all recordings will be destroyed. The information you provide during the interview will be transcribed and analysed for our study reports. Some quotations from the group discussion may appear in our study reports but we will take care to ensure that you cannot be identified.

- Voluntary participation/withdrawal: Your child's participation in this study is completely up to him/her. If you decide not to allow him/her to participate, $\mathrm{s} / \mathrm{he}$ will not lose any existing benefits to which s/he is entitled as a student. If you agree to let your child participate in this study, you may end his/her participation at any time without penalty or loss of existing benefits to which he/she is entitled. You are free to withdraw at any time without affecting your relationship with the study team, your child's school or health providers.

- Outcome and Feedback: The results of the study will be used to design an adolescent reproductive health program for adolescents in Ghana and will also be presented at conferences and published in journals.

- Funding information: Population Council Ghana conducts this study in collaboration with funding from the UK Government (Department for International Development) under the Step-Up study. 
- Who has reviewed the study for ethical issues? This study has been reviewed by Population Council IRB and the Ghana Health Service Ethical Review Committee.

Who to Contact for Clarification: If you have a concern about any aspect of the study, you should ask to speak to the researchers who will do their best to answer your questions. You may also call Terence Adda-Balinia, Program Officer, Population Council, Accra, Ghana at Tel: +233 302 780711/2, Mob: +233 244843790, email: taddabalinia@popcouncil.org. or Ms. Hannah Frimpong, Administrator, Ghana Health Service Ethical Review Committee, Research and Development Division, Ghana Health Service, P. O. Box MB190, Accra at Mobile 2330243235225 / 2330507041223 email: hannah.frimpong@ghsmail.org

\section{CONSENT FORM PARENT/GUARDIAN PERMISSION}

\section{B. PARTICIPANT STATEMENT AND SIGNATURE}

I certify that I voluntarily agree to let my ward participate in this study, that the study has been explained to me. All my questions have been answered satisfactorily. I understand I am free to discontinue my ward's participation at any time if I so choose.

Signature or thumbprint of Participant

(Thumbprint for those who cannot read and write)

Date

\section{INVESTIGATOR STATEMENT AND SIGNATURE}

I certify that the participant has been given ample time to read and learn about the study. All questions and clarifications raised by the participant have been addressed.

Signature of person who sought consent

Date 


\section{Appendix 3 FGD parent Information sheet and consent forms}

\section{INFORMATION SHEET}

ii. Title of Study: Acceptability and feasibility of introducing strengthened schoolbased sexual and reproductive health information and services in Accra, Ghana

iii. Introduction: You are invited to take part in a research study. Before you decide whether to participate, you need to understand why the research is being done and what it would involve. Please take the time to read or to listen as I read the following information. You may talk to others about the study if you wish. Please ask me if there is anything that is not clear, or if you would like more information. When all of your questions have been answered and you feel that you understand this study, you will be asked if you wish to participate in the study, and if yes to sign this Informed Consent form. You will be given a signed copy to keep. Please keep the information you hear in the group confidential. This study is been conducted under the leadership of the following people:

Name: Terence Adda-Balinia

(Principal Investigator in Ghana)

Program Officer,

Population Council Ghana

Box CT 4906, Cantonments

Tel: +233 $302780711 / 2$

Email: taddabalinia@popcouncil.org
Name: Dr. Tapsoba L. Placide

(Co-investigator for the study)

Country Director

Population Council Ghana

Box CT 4906, Cantonments

+233302 780711/2

ptabsoba@popcouncil.org

Population Council Ghana conducts this study) under the STEP UP (Strengthening Evidence for Programming on Unintended Pregnancy) Research Programme Consortium which generates policy-relevant research to promote an evidence-informed approach for improving access to sexual and reproductive health services.

iv. Nature of research: We are conducting social research on adolescent sexual and reproductive health programming in Ghana. The purpose of the study is to find out perceptions about the adequacy of the current sexuality education in schools and views about the introduction of a comprehensive sexuality education in schools which include enhancing the content of the existing life skills/POP/FLE education and strengthening the delivery of SRH information and services in schools. You have been invited to take part because you have an adolescent who lives in this community and is currently receiving education in one of the target schools

\section{v. Participants involvement:}

- Duration /what is involved: If you agree to take part in the study, we will ask you to sign this form. You will also be asked to share information on adolescent reproductive health issues taught in school and your views on a proposed introduction of a comprehensive sexuality curriculum in schools. This will take about an hour of your time. We may contact you again if we need to follow-up 
on issues discussed with your child or an official from Population Council might visit to verify your informed consent.

- Potential Risks: An inconvenience may be the time and effort you take to be a participant. You may find one or more questions that we ask to be upsetting or emotionally sensitive. You do not have to respond to any question that makes you uncomfortable. You may end the focus group at any time without penalty or loss of any benefits to which you are entitled. A risk may be a breach of confidentiality (something you say during the focus group is shared with others outside the group) but we will take precautions to see that this does not happen.

- Benefits: There are no direct benefits to you for participating in the study. You may find an indirect benefit in knowing you have participated in an important study that could help others in the future

- Compensation/Payment: No compensation will be given for participation in the study, but we will provide a little snack (a drink and a pack of food) will be made available to you after the discussion

- Confidentiality: The information that is collected during the interview will be kept private. No one will be told that you have participated in the study. Other focus group participants will know what you say during the focus group discussion. However, we will ask participants to keep information shared during the focus group confidential. The information that is collected during the focus group and the other interviews will be used to design an adolescent reproductive health program for adolescents in Ghana. The study team will make every effort to protect your privacy and maintain the confidentiality of all the information that you provide. Your name or other identifiers will not be included in any published documents from this study. Data will be stored in a computer dedicated to this study that only the study team can access. All audio-recorded interviews will be handled only by the research team and stored at Population Council Ghana for a period of five years after which all recordings will be destroyed.

- Voluntary participation/withdrawal: Your participation in this study is completely voluntary. If you decide not to participate, you will not lose any existing benefits to which you are entitled. If you agree to participate in this study, you may end your participation at any time without penalty or loss of existing benefits to which you are entitled. If you decide to take part, you are free to refrain from answering any questions. You are free to withdraw at any time without affecting your relationship with the study team, school officials or health care providers.

- Outcome and Feedback: The results of the study will be used to design an adolescent reproductive health program for adolescents in Ghana and will also be presented at conferences and published in journals.

- Funding information: Population Council Ghana conducts this study in collaboration with funding from the UK Government (Department for International Development) under the Step-Up study.

- Who has reviewed the study for ethical issues? This study has been reviewed by Population Council IRB and the Ghana Health Service Ethical Review Committee. 
- Who to Contact for Clarification: If you have a concern about any aspect of the study, you should ask to speak to the researchers who will do their best to answer your questions. You may also call Terence Adda-Balinia, Program Officer, Population Council, Accra, Ghana at Tel: +233 302 780711/2, Mob: +233 244843790, email: taddabalinia@ popcouncil.org. or Ms. Hannah Frimpong, Administrator, Ghana Health Service Ethical Review Committee, Research and Development Division, Ghana Health Service, P. O. Box MB190, Accra at Mobile 2330243235225 / 2330507041223 email:

hannah.frimpong@ghsmail.org

\section{CONSENT FORM FOR PARENT FGD PARTICIPANTS}

\section{PARTICIPANT STATEMENT AND SIGNATURE}

I certify that I voluntarily agree to answer the study questions, that the study has been explained to me. All my questions have been answered satisfactorily. I understand I am free to discontinue participation at any time if I so choose.

Signature or thumbprint of Participant

(Thumbprint for those who cannot read and write)

Date

Note: If participants are unable to read the form themselves. A witness must sign declaring they were present while the benefits, risks and procedures were read to the participants and all questions were answered and the participant has agreed to take part in the research.

Signature or thumbprint of Witness

\section{INVESTIGATOR STATEMENT AND SIGNATURE}

I certify that the participant has been given ample time to read and learn about the study. All questions and clarifications raised by the participant have been addressed.

Signature of person who sought consent

Date 


\section{Appendix 4 FGD teachers Information sheet and consent forms}

\section{INFORMATION SHEET}

ii. Title of Study: Acceptability and feasibility of introducing strengthened schoolbased sexual and reproductive health information and services in Accra, Ghana

iii. Introduction: You are invited to take part in a research study. Before you decide whether to participate, you need to understand why the research is being done and what it would involve. Please take the time to read or to listen as I read the following information. You may talk to others about the study if you wish. Please ask me if there is anything that is not clear, or if you would like more information. When all of your questions have been answered and you feel that you understand this study, you will be asked if you wish to participate in the study, and if yes to sign this Informed Consent form. You will be given a signed copy to keep. Please keep the information you hear in the group confidential. This study is being conducted under the leadership of the following people:

Name: Terence Adda-Balinia

(Principal Investigator in Ghana)

Program Officer,

Population Council Ghana

Box CT 4906, Cantonments

Tel: +233 $302780711 / 2$

Email: taddabalinia@popcouncil.org
Name: Dr. Tapsoba L. Placide

(Co-investigator for the study)

Country Director

Population Council Ghana

Box CT 4906, Cantonments

+233302 780711/2

ptabsoba@popcouncil.org

Population Council Ghana conducts this study) under the STEP UP (Strengthening Evidence for Programming on Unintended Pregnancy) Research Programme Consortium which generates policy-relevant research to promote an evidence-informed approach for improving access to sexual and reproductive health services.

iv. Nature of research: We are conducting social research on adolescent sexual and reproductive health programming in Ghana. The purpose of the study is to find out perceptions about the adequacy of the current sexuality education in schools and views about the introduction of a comprehensive sexuality education in schools which include enhancing the content of the existing life skills/POP/FLE education and strengthening the delivery of SRH information and services in schools. You have been invited to take part because you are a teacher who lives in this community and is currently providing sexuality education in one of the target schools

\section{v. Participants involvement:}

- Duration /what is involved: If you agree to take part in the study, we will ask you to sign this form. You will also be asked to share information on adolescent reproductive health issues taught in school and your views on a proposed introduction of a comprehensive sexuality curriculum in schools. This will take 
about an hour of your time. We may contact you again if we need to follow-up on issues discussed or an official from Population Council might visit to verify your informed consent.

- Potential Risks: An inconvenience may be the time and effort you take to be a participant. You may find one or more questions that we ask to be upsetting or emotionally sensitive. You do not have to respond to any question that makes you uncomfortable. You may end the focus group at any time without penalty or loss of any benefits to which you are entitled. A risk may be a breach of confidentiality (something you say during the focus group is shared with others outside the group) but we will take precautions to see that this does not happen.

- Benefits: There are no direct benefits to you for participating in the study. You may find an indirect benefit in knowing you have participated in an important study that could help others in the future

- Compensation/Payment: No compensation will be given for participation in the study, but we will provide a little snack (non-alcoholic drink and a pack of food) will be made available to you after the discussion

- Confidentiality: The information that is collected during the interview will be kept private. No one will be told that you have participated in the study. Other focus group participants will know what you say during the focus group discussion. However, we will ask participants to keep information shared during the focus group confidential. The information that is collected during the focus group and the other interviews will be used to design an adolescent reproductive health program for adolescents in Ghana. The study team will make every effort to protect your privacy and maintain the confidentiality of all the information that you provide. Your name or other identifiers will not be included in any published documents from this study. Data will be stored in a computer dedicated to this study that only the study team can access. All audio-recorded interviews will be handled only by the research team and stored at Population Council Ghana for a period of five years after which all recordings will be destroyed.

- Voluntary participation/withdrawal: Your participation in this study is completely voluntary. If you decide not to participate, you will not lose any existing benefits to which you are entitled. If you agree to participate in this study, you may end your participation at any time without penalty or loss of existing benefits to which you are entitled. If you decide to take part, you are free to refrain from answering any questions. You are free to withdraw at any time without affecting your relationship with the study team, school officials or health care providers.

- Outcome and Feedback: The results of the study will be used to design an adolescent reproductive health program for adolescents in Ghana and will also be presented at conferences and published in journals.

- Funding information: Population Council Ghana conducts this study in collaboration with funding from the UK Government (Department for International Development) under the Step-Up study.

- Who has reviewed the study for ethical issues? This study has been reviewed by Population Council IRB and the Ghana Health Service Ethical Review Committee. 
- Who to Contact for Clarification: If you have a concern about any aspect of the study, you should ask to speak to the researchers who will do their best to answer your questions. You may also call Terence Adda-Balinia Officer, Population Council, Accra, Ghana at Tel: +233302 780711/2, Mob: +233 244843790, email: taddabalinia@ @opcouncil.org. or Ms. Hannah Frimpong, Administrator, Ghana Health Service Ethical Review Committee, Research and Development Division, Ghana Health Service, P. O. Box MB190, Accra at Mobile 2330243235225 / 2330507041223 email:

hannah.frimpong@ghsmail.org

\section{CONSENT FORM FOR PARENT FGD PARTICIPANTS}

\section{PARTICIPANT STATEMENT AND SIGNATURE}

I certify that I voluntarily agree to answer the study questions, that the study has been explained to me. All my questions have been answered satisfactorily. I understand I am free to discontinue participation at any time if I so choose.

Signature or thumbprint of Participant

(Thumbprint for those who cannot read and write)

Date

Note: If participants are unable to read the form themselves. A witness must sign declaring they were present while the benefits, risks and procedures were read to the participants and all questions were answered and the participant has agreed to take part in the research.

Signature or thumbprint of Witness

\section{INVESTIGATOR STATEMENT AND SIGNATURE}

I certify that the participant has been given ample time to read and learn about the study. All questions and clarifications raised by the participant have been addressed.

Signature of person who sought consent

Date 


\section{Appendix 5: Key stakeholders parent Information sheet and consent form}

\section{INFORMATION SHEET}

ii. Title of Study: Acceptability and feasibility of introducing strengthened schoolbased sexual and reproductive health information and services in Accra, Ghana

iii. Introduction: You are invited to take part in a research study. Before you decide whether to participate, please allow me to explain why the research is being done and what it would involve. Please take the time to read or to listen as I read the following information. Please stop me at any time to ask questions if there is anything that is not clear, or if you would like more information. When all of your questions have been answered and you feel that you understand this study, you will be asked whether you wish to participate in the study or not. If you do, you will be asked to sign this Informed Consent form. You will be given a signed copy to keep. You may talk to others about the study if you wish. This study is being conducted under the leadership of the following people:

Name: Terence Adda-Balinia

(Principal Investigator in Ghana)

Program Officer,

Population Council Ghana

Box CT 4906, Cantonments

Tel: +233 $302780711 / 2$

Email: taddabalinia@popcouncil.org
Name: Dr. Tapsoba L. Placide

(Co-investigator for the study)

Country Director

Population Council Ghana

Box CT 4906, Cantonments

+233302 780711/2

ptabsoba@popcouncil.org

Population Council Ghana conducts this study under the STEP UP (Strengthening Evidence for Programming on Unintended Pregnancy) Research Programme Consortium which generates policy-relevant research to promote an evidence-informed approach for improving access to sexual and reproductive health services.

iv. Nature of research: We are conducting social research on adolescent sexual and reproductive health programming in Ghana. The purpose of the study is to find out your perceptions about the adequacy of the current sexuality education in schools and your views about the introduction of comprehensive sexuality education in schools. Comprehensive sexuality education includes enhancing the content of the existing life skills/POP/FLE education and strengthening the delivery of SRH information and services in schools. You have been invited to take part because you are a key stakeholder in the development and implementation of ASRH education in schools. v. Participants involvement:

- Duration /what is involved: If you agree to take part in the study, we will ask you to sign this form. You will also be asked to respond to questions regarding your views on adolescent reproductive health issues taught in school and on a proposed introduction of a comprehensive sexuality curriculum in schools. This 
will take about 45 minutes. We may contact you again if we need to follow-up on issues discussed with you or an official from Population Council might visit to verify your informed consent.

- Potential Risks: An inconvenience may be the time and effort you take to be a participant. You may find one or more questions that we ask to be discomforting, emotionally sensitive or upsetting. You do not have to respond to any question that makes you uncomfortable. You may end the interview at any time without penalty. A risk may be a breach of confidentiality (something you say that is accidentally provided to others), but we will take precautions to see that this does not happen.

- Benefits: There are no direct benefits to you for participating in the study. You may find an indirect benefit in knowing you have participated in an important study that could help youth in Ghana.

- Compensation/Payment: No compensation will be given for participation in the study, but the information that you provide will contribute to the muchneeded evidence for adolescent in-school SRH programing to benefit the community and the country as a whole.

- Confidentiality: The information that is collected during the interview will be kept private. No one will be told that you have participated in the study. The study team will make every effort to protect your privacy and maintain the confidentiality of all the information that you provide. Your name or other identifiers will not be included in published documents from this study. Data will be stored in a computer dedicated to this study that only the study team can access. We will not share any of your information with your parents. All audiorecorded interviews will be handled only by the research team and stored at Population Council Ghana for a period of five years after which all recordings will be destroyed.

- Voluntary participation/withdrawal: Your participation in this study is completely up to you. If you decide not to participate, you will not lose any existing benefits to which you are entitled. If you agree to participate in this study, you may end your participation at any time without penalty or loss of existing benefits to which you are entitled. If you decide to take part, you are free to skip any questions. You are free to withdraw at any time without affecting your relationship with the study team or the teaching and health communities.

- Outcome and Feedback: The results of the study will be used to design an adolescent reproductive health program for adolescents in Ghana and will also be presented at conferences and published in journals.

- Funding information: Population Council Ghana conducts this study in collaboration with funding from the UK Government (Department for International Development) under the Step-Up study.

- Who has reviewed the study for ethical issues? This study has been reviewed by Population Council IRB and the Ghana Health Service Ethical Review Committee.

Who to Contact for Clarification: If you have a concern about any aspect of the study, you should ask to speak to the researchers who will do their best to answer your questions. You may also call Terence Adda-Balinia Program Officer, Population 
Council, Accra, Ghana at Tel: +233302 780711/2, Mob: +233 244843790, email: taddabalinia@ popcouncil.org. or Ms. Hannah Frimpong, Administrator, Ghana Health Service Ethical Review Committee, Research and Development Division, Ghana Health Service, P. O. Box MB190, Accra at Mobile 2330243235225 / 2330507041223 email: hannah.frimpong@ghsmail.org 


\section{CONSENT FORM FOR KEY STAKEHOLDERS}

\section{PARTICIPANT STATEMENT AND SIGNATURE}

I certify that I voluntarily agree to answer the study questions, that the study has been explained to me. All my questions have been answered satisfactorily. I understand I am free to discontinue participation at any time if I so choose.

Signature or thumbprint of Participant

(Thumbprint for those who cannot read and write)

Date

INVESTIGATOR STATEMENT AND SIGNATURE

I certify that the participant has been given ample time to read and learn about the study. All questions and clarifications raised by the participant have been addressed.

Signature of person who sought consent

Date 
Appendix 6: List of Schools in Nima

GHANA EDUCATION SERVICE (AYAWASO EAST SUB:METROEDUCATION OFEICE)

or Ret Na

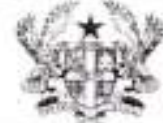

AEPU⿴囗K OF GHAN

P O, Box AN 5398

Acera North

Tot 0206983373

\section{JHS ENROLMENT}

\begin{tabular}{|c|c|c|c|c|c|c|c|c|c|c|c|c|}
\hline \multirow[t]{2}{*}{ SN } & \multirow[t]{2}{*}{ NAME OF SCHOOL } & \multirow[t]{2}{*}{ CIRCUIT } & \multicolumn{3}{|c|}{ JHS1 } & \multicolumn{3}{|c|}{ JHS2 } & \multicolumn{3}{|c|}{ JHS3 } & \multirow{2}{*}{ TOTAL } \\
\hline & & & B & $G$ & $T$ & B & G & $T$ & B & G & $T$ & \\
\hline 1 & $\begin{array}{l}\text { AL-WALEED } \\
\text { COMPREHENSIVE }\end{array}$ & KANDA 15 & 25 & 25 & 50 & 29 & 23 & 52 & 30 & 25 & 55 & 157 \\
\hline 2 & $\begin{array}{l}\text { ISLAMIC TRAINING } \\
\text { INSTITUTE }\end{array}$ & KANDA 15 & 13 & 12 & 25 & 9 & 11 & 20 & 10 & 8 & 18 & 63 \\
\hline 3 & KANDA AMA & KANDA 15 & 28 & 32 & 60 & 27 & 26 & 53 & 20 & 21 & 41 & 154 \\
\hline 4 & KANDA ESTATE 1 & KANDA 15 & 30 & 30 & 60 & 28 & 31 & 59 & 33 & 27 & 60 & 179 \\
\hline 5 & KANDA ESTATE 5 & KANDA 15 & 37 & 41 & 78 & 42 & 45 & 87 & 43 & 40 & 83 & 248 \\
\hline 6 & RING ROAD EAST 1 & KANDA 15 & 23 & 28 & 51 & 16 & 13 & 29 & 22 & 18 & 40 & 120 \\
\hline 7 & NIMA 1 & NIMA 17 & 25 & 30 & 55 & 29 & 18 & 47 & 19 & 46 & 65 & 147 \\
\hline 8 & NIMA 2 & NIMA 17 & 34 & 40 & 74 & 31 & 32 & 63 & 25 & 35 & 60 & 197 \\
\hline 9 & ST, KIZITO 1 & NIMA 17 & 26 & 23 & 49 & 22 & 27 & 49 & 17 & 26 & 43 & 141 \\
\hline 10 & ST. KIZITO 2 & NIMA 17 & 18 & 26 & 44 & 19 & 24 & 43 & 28 & 28 & 56 & 143 \\
\hline 11 & $\begin{array}{l}\text { INSTITUTE OF ISLAMIC } \\
\text { STOS. }\end{array}$ & NIMA 17 & 25 & 45 & 70 & 26 & 36 & 62 & 30 & 31 & 61 & 193 \\
\hline 12 & ST, FRANCIS XAVIER & $\begin{array}{l}\text { KOTOBABI } \\
19\end{array}$ & 30 & 39 & 69 & 28 & 41 & 69 & 25 & 27 & 52 & 190 \\
\hline 13 & UNITY JHS & $\begin{array}{l}\text { КOTOBABI } \\
19\end{array}$ & 54 & 68 & 122 & 39 & 57 & 96 & 17 & 36 & 65 & 283 \\
\hline 14 & КОТОВАВI 13 & $\begin{array}{l}\text { KOTOBABI } \\
19\end{array}$ & 50 & 50 & 100 & 58 & $4 t$ & 99 & 45 & 33 & 78 & 277 \\
\hline & TOTAL & & & & 907 & & & 828 & & & 777 & 2492 \\
\hline
\end{tabular}

Price

$$
29 / 7 / 13
$$




\section{Appendix 7: In-depth Inteview Guide for Key stakeholders: GES, GHS and Key Officials of NGOs}

ID number:

Date of interview:

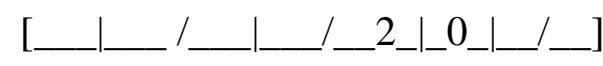

Time of interview:

Start [

End [

Venue of interview:

Type of institution:

Sex of participant: $\quad$ Male [__ ] Female [__ $]$

\section{Introduction:}

Thank you for your willingness to take part in the discussion. Your opinions will be most helpful for understanding how best to reach young people in Ghana with sexual and reproductive health information and services to help them avoid risky behaviors and undesired consequences that can negatively affect their life trajectories.

\section{Views regarding the provision of sexual and reproductive health information and services}

a. What is your opinion regarding the provision of sexual and reproductive health information in schools? [Probe for reasons for or against the provision of such information in schools

- [If negative opinion about schools] Where would you prefer that young people obtain sexual and reproductive health information if they need it?

- What are some of the advantages the source(s) of sexual and reproductive health information you have mentioned, [probe for advantages of over schools]?

- [If parents/guardians are not mentioned, ask:] What are your opinions about parents/guardians providing such information to their children/adolescents? [Probe for reasons for or against parents/guardians providing information]

b. What is your opinion regarding the provision of sexual and reproductive health services in schools? [Probe for reasons for/against provision of such services in schools; Probe for perceived utility (or inutility) of these services to students]

- [If negative opinion about schools] Where would you prefer that young people obtain sexual and reproductive health services if they need them?

- What are some of the advantages the source(s) of sexual and reproductive health services you have mentioned, [probe for advantages of over schools]? 


\section{Views regarding enhanced comprehensive sexuality education}

- In Ghana today, youth in schools are mainly taught abstinence-based sexuality education, usually by multiple teachers.

- What are your views on the content of sexuality education in schools? [Probe on adequacy and on usefulness to students of adolescent age]. What is your opinion, how much room is there for improvement of the content of the existing Population and Family Life Education curriculum?

- If yes, how can the content of the curriculum be improved to ensure that it meets the needs of youth and help them live healthy lives? [Probe for what needs to be added, removed or improved upon]

- In your opinion, what processes should be put in place to improve the content of the curriculum?

- What challenges, if any, do you envisage may arise as a result of the improvements you have suggested?

- [If no room for improvement], please discuss your reasons against improving the current curriculum.

- What is your opinion regarding visits to schools by trained experts such as psychologists to provide sexual and reproductive health information?

- [If favorable] What benefit do you foresee from having trained psychologists visit schools to provide sexual and reproductive health information?

- [If favorable], In your opinion, what processes will need to be put in place for this approach of using trained psychologists to be successful?

- [If favorable] What challenges, if any, do you think may arise as a result of having trained experts visit schools to provide sexual and reproductive health information?

- [If not favorable] Please discuss your reservations and/or reasons against having trained psychologists visit schools to provide sexual and reproductive health information? [Probe for source of reservation: structural, personal, religious, political, etc.]

- Likewise, what is your opinion regarding visits to schools by trained health care providers to provide sexual and reproductive health services? [Services include counselling].

- Do you feel that there is anything we have left out or is there anything additional that you would like to contribute regarding the provision of sexual and reproductive health information and services to young people in school?

- Is there any other related issue that you would like raise?

\section{THANK YOU VERY MUCH FOR YOUR TIME}




\section{Appendix 8: Focus Group Discussion Guide for In-school Adolescents}

Date of discussion:

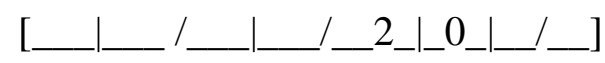

Time of discussion:

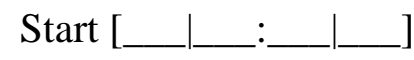

End [

Venue of discussion:

List of participants:

\begin{tabular}{|l|l|l|}
\hline $\begin{array}{l}\text { PARTICIPANT } \\
\text { NUMBER }\end{array}$ & $\begin{array}{l}\text { PARTICIPANT'S SEX } \\
\text { (MALE OR FEMALE) }\end{array}$ & $\begin{array}{l}\text { PARTICIPANT'S } \\
\text { AGE (YEARS) }\end{array}$ \\
\hline Participant 1 & & \\
\hline Participant 2 & & \\
\hline Participant 3 & & \\
\hline Participant 4 & & \\
\hline Participant 5 & & \\
\hline Participant 6 & & \\
\hline Participant 7 & & \\
\hline Participant 8 & & \\
\hline Participant 9 & & \\
\hline Participant 10 & & \\
\hline
\end{tabular}

Moderator's notes (if any):

\section{Introduction:}

Welcome. Thank you for your willingness to take part in this discussion. Your opinions will be most helpful for understanding how best to reach young people in Ghana with sexual and reproductive health information and services to help them avoid risky behaviors and undesired consequences that can negatively affect their life and future. 


\section{Views regarding the provision of sexual and reproductive health information and services}

- How important is school to you?

- What types of information do you learn only from school?

- What type of information have you learned in school about your health?

- What do you understand when we say, "adolescent sexual and reproductive health"?

\section{a. Access to sexual and reproductive health information}

- What kind of sexual and reproductive health information, if any, have you been taught in school?

- From which sources within the school do you obtain sexual and reproductive health information? [Probe for sources such as formal lessons, guidance/counseling sessions, school clubs, printed materials (e.g. booklets, leaflets, charts), health talks by guest speakers, and school clinic/nurse/matron if any].

- Is there anyone else who you think could also teach these topics?

If so, who? And why?

- What is your opinion (or how do you feel) about being taught sexual and reproductive health information in school?

- What are some of the benefits of teaching sexual and reproductive health information to young people your age?

$\circ$ What are some of the problems or challenges of teaching sexual and reproductive health information to young people your age?

a.

\section{Other sources of ASRH information}

- Apart from school, where else do young people of your age get sexual and reproductive health information if you need it?

$>$ What are the reasons why you obtain information from the sources you have mentioned?

What kind of information do you obtain from the sources you have mentioned?

○ Of the sources you have mentioned, which ones are your most preferred?

- What makes these sources most the most preferred for getting sexual and reproductive health information? 


\section{b. Access to sexual and reproductive health services}

c. Now we are going to talk about your views on providing sexual and reproductive health services in schools. What comes to mind when we say sexual and reproductive health services?

a. What types of sexual and reproductive services have you heard of?

\section{[Provide examples of services that are not brought up spontaneously]}

- What is your opinion (or how do you feel) about sexual and reproductive health services being provided in school?

- What are some of the benefits of providing sexual and reproductive health services to young people your age?

- What are some of the problems or challenges of providing sexual and reproductive health services to young people of your age?

a. What kind of sexual and reproductive health services, if any, do you receive in school?

- From what sources within the school do you obtain sexual and reproductive health services? [Probe for sources such as guidance/counseling teachers, school clubs, and outreach by health facility/providers and school clinic/nurse/matron if any].

- Is there anyone else who you think could also provide these services?

$\circ$ If so, who? And why?

- If not in school, where else do young people your age get sexual and reproductive health services, if they need them?

$\circ$ Of the sources you have mentioned, which ones do you think are the most preferred by young people of your age?

- Why do young people of your age prefer to obtain sexual and reproductive health services from the sources you have mentioned? 


\section{Other sources of ASRH services}

- Apart from school, where else do young people of your age get sexual and reproductive health services if they need them?

$>$ What are the reasons why young people of our age obtained services from the sources you have mentioned?

$>$ What kind of services do young people of your age get from the sources you have mentioned?

$\circ$ Of the sources you have mentioned, which ones are your most preferred?

$\circ$ What makes these sources most the most preferred for getting sexual and reproductive health services?

\section{Views regarding enhanced comprehensive sexuality education}

- In Ghana today, young people in schools are mainly taught to abstain from sex. What are your views on what you are being taught about sexuality in schools? [Probe on adequacy and on usefulness to students of adolescent age]

- In your opinion, can the information or curriculum currently being taught be improved?

- If yes, how can the content of the curriculum be improved to ensure that it meets the needs of youth and help you live healthy lives? [Probe for what needs to be added, removed or improved upon]

○ In your opinion, what needs to be done to improve the content of the curriculum?

- What challenges, if any, do you think may come from making the improvements you have suggested?

- [If the information cannot be improved] For those who don't think the information or curriculum can be improved, please tell us your reasons why there can be no improvement.

- How many of you have ever heard of a psychologist? Who can tell us what a psychologist does?

- Some people have suggested bringing trained experts such as psychologists to provide sexual and reproductive health information to young people in schools? What are your thoughts on this suggestion?

- [If favorable] What benefit(s) do you think can come from having trained psychologists visit schools to provide sexual and reproductive health information to young people like yourselves? 
- [If favorable], in your opinion, what will need to be done by the school or the government so that trained psychologists can visit schools?

- [If favorable] What difficulties, if any, do you think may come from having trained experts visit schools to provide sexual and reproductive health information to young people like yourselves?

- [If not favorable] Some of you have doubts that bringing psychologists will help young people in schools. Please tell us about your reasons for these doubts. [Probe for source of reservation: structural, personal, religious, political, etc.]

We have just talked about your views about having trained psychologists visit schools to provide information on sexual and reproductive health to young people. Now we will talk about health care providers.

- What are your views about having trained health care providers visiting schools by to provide sexual and reproductive health services?

- [If favorable] What benefit(s) do you think having trained health care providers visit schools to provide sexual and reproductive health services will bring for young people of your age?

- [If favorable], In your opinion, what will need to be done by the school or the government so that trained health care providers can visit schools to provide services?

- [If favorable] What difficulties, if any, do you think may come from having trained health care providers visit schools to provide sexual and reproductive health services to young people?

- [If not favorable] Some of you have doubts that bringing health care providers will help young people in schools. Please tell us about your reasons for these doubts. [Probe for source of reservation: structural, personal, religious, political, etc.]

- Do you feel that there is anything we have left out or is there anything additional that you would like to contribute regarding the provision of sexual and reproductive health information and services to young people in school?

- Is there any other related issue that you would like raise?

We have now come to the end of our discussion.

THANK YOU VERY MUCH FOR YOUR TIME 


\section{Appendix 9: Focus Group Discussion Guide for Parents}

Date of discussion:

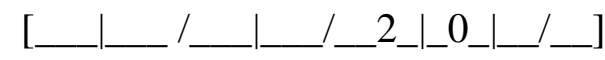

Time of discussion:

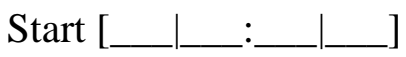

End [

Venue of discussion:

List of participants:

\begin{tabular}{|l|l|l|}
\hline $\begin{array}{l}\text { PARTICIPANT } \\
\text { NUMBER }\end{array}$ & $\begin{array}{l}\text { PARTICIPANT'S SEX } \\
\text { (MALE OR FEMALE) }\end{array}$ & $\begin{array}{l}\text { PARTICIPANT'S } \\
\text { AGE (YEARS) }\end{array}$ \\
\hline Participant 1 & & \\
\hline Participant 2 & & \\
\hline Participant 3 & & \\
\hline Participant 4 & & \\
\hline Participant 5 & & \\
\hline Participant 6 & & \\
\hline Participant 7 & & \\
\hline Participant 8 & & \\
\hline Participant 9 & & \\
\hline Participant 10 & & \\
\hline
\end{tabular}

Moderator's notes (if any):

\section{Introduction:}

5. Thank you for your willingness to take part in the discussion. Your opinions will be most helpful for understanding how best to reach young people in Ghana with 
sexual and reproductive health information and services to help them avoid negative consequences such as unplanned pregnancies.

Views regarding the provision of sexual and reproductive health information and services to young people

a. What are your opinions regarding providing sexual and reproductive health information to young people in schools? [Probe for reasons for or against the provision of such information in school]

b. What are your opinions regarding providing sexual and reproductive health services to young people in schools? [Probe for reasons for or against the provision of such services in school]

c. [If opinions about young people obtaining sexual and reproductive health information and services in schools are positive, begin: Apart from school...] Where would you prefer that our young people obtain sexual and reproductive health information and services if they need them?

- Why do prefer that our young people obtain sexual and reproductive health services from the sources you have mentioned?

- [If parents/guardians are not mentioned, ask:] What are your opinions about parents/guardians providing such information to young people? [Probe for reasons for or against parents/guardians providing information]

\section{Views regarding enhanced comprehensive sexuality education}

b. Based on what you know about the current situation regarding the provision of sexual and reproductive health information and services to young people in schools:

- What changes, if any, are needed to ensure that young people get the information that they need to help them live healthy lives?

- What changes, if any, are needed to ensure that young people obtain the services they need in order to avoid negative sexual and reproductive health consequences?

- What challenges, if any, do you think may come up when making the changes you have mentioned?

c. Now we are going to talk about some changes that have been proposed elsewhere as ways of improving access to sexual and reproductive health information and services for in-school young people. These include improving the content of the existing Population and Family Life Education curriculum and having trained experts such as psychologists and health care providers visit schools to provide sexual and reproductive health information or services.

- What are your opinions regarding improving the existing Population and Family Life Education curriculum? [Probe for reasons for and against improving the curriculum]

$>$ In your opinions, how should the content of the curriculum be improved to ensure that it meets the needs of learners? [Probe for what needs to be added, removed or improved upon] 
What challenges, if any, do you think may arise as a result of the improvements you have suggested?

- What are your opinions regarding having trained experts such as psychologists and health care providers visit schools to provide sexual and reproductive health information or services? [Probe for reasons for and against using trained experts]

$>$ What challenges, if any, do you think may arise as a result of having trained experts visit schools to provide sexual and reproductive health information or services?

\section{We have now come to the end of our discussion.}

- Do you feel that there is anything we have left out or is there something you would like to mention regarding the provision of sexual and reproductive health information and services to young people?

- Is there any other general issue you would like raise?

\section{THANK YOU VERY MUCH FOR YOUR TIME}




\section{Appendix 10: Focus Group Discussion Guide for Teachers}

Date of discussion:

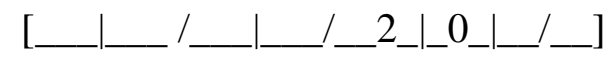

Time of discussion:

Start

End [

Venue of discussion:

List of participants:

\begin{tabular}{|l|l|l|}
\hline $\begin{array}{l}\text { PARTICIPANT } \\
\text { NUMBER }\end{array}$ & $\begin{array}{l}\text { PARTICIPANT'S SEX } \\
\text { (MALE OR FEMALE) }\end{array}$ & $\begin{array}{l}\text { PARTICIPANT'S } \\
\text { AGE (YEARS) }\end{array}$ \\
\hline Participant 1 & & \\
\hline Participant 2 & & \\
\hline Participant 3 & & \\
\hline Participant 4 & & \\
\hline Participant 5 & & \\
\hline Participant 6 & & \\
\hline Participant 7 & & \\
\hline Participant 8 & & \\
\hline Participant 9 & & \\
\hline Participant 10 & & \\
\hline
\end{tabular}

Moderator's notes (if any):

\section{Introduction:}

Thank you for your willingness to take part in the discussion. Your opinions will be most helpful for understanding how best to reach young people in Ghana with sexual and reproductive health information and services to help them avoid negative consequences such as unplanned pregnancies. 


\section{Views regarding the provision of sexual and reproductive health information and services}

c. What is your opinion regarding providing sexual and reproductive health information in schools? [Probe for reasons for or against the provision of such information in schools]

- Where would you prefer that young people obtain sexual and reproductive health information if they need it?

- Why do you prefer that young people obtain sexual and reproductive health information from the sources you have mentioned?

- [If parents/guardians are not mentioned, ask:] What are your opinions about parents/guardians providing such information to young people? [Probe for reasons for or against parents/guardians providing information]

d. What is your opinion regarding providing sexual and reproductive health services in schools? [Probe for reasons for or against the provision of such services in schools]

- Where would you prefer that young people obtain sexual and reproductive health services if they need them?

- Why do you prefer that young people obtain sexual and reproductive health services from the sources you have mentioned?

\section{Views regarding enhanced comprehensive sexuality education}

d. Based on what you know about the current situation regarding the provision of sexual and reproductive health information and services to young people in schools:

- What changes, if any, are needed to ensure that in-school young people get the information that they need to help them live healthy lives?

- What changes, if any, are needed to ensure that in-school young people obtain the services they need in order to avoid negative sexual and reproductive health consequences?

- What challenges, if any, do you think may come up when making the changes you have mentioned?

e. Now we are going to talk about some specific changes that have been proposed elsewhere as ways of improving access to sexual and reproductive health information and services for in-school young people. These include improving the content of the existing Population and Family Life Education curriculum and having trained experts such as psychologists and health care providers visit schools to provide sexual and reproductive health information or services.

- What is your opinion regarding improving the content of the existing Population and Family Life Education curriculum? [Probe for reasons for and against improving the curriculum] 
- In your opinion, how should the content of the curriculum be improved to ensure that it meets the needs of learners? [Probe for what needs to be added, removed or improved upon]

- In your opinion, what processes should be put in place to improve the content of the curriculum?

- What challenges, if any, do you think may arise as a result of the improvements you have suggested?

- What is your opinion regarding having trained experts such as psychologists and health care providers visit schools to provide sexual and reproductive health information or services? [Probe for reasons for and against using trained experts]

- In your opinion, what processes need to be put in place for the approach of using experts to be successful?

- What challenges, if any, do you think may arise as a result of having trained experts visit schools to provide sexual and reproductive health information or services?

\section{We have now come to the end of our discussion.}

- Do you feel that there is anything we have left out or is there something you would like to mention regarding the provision of sexual and reproductive health information and services to in-school young people?

- Is there any other general issue you would like raise?

\section{THANK YOU VERY MUCH FOR YOUR TIME}




\section{www.stepup.popcouncil.org}

The STEP UP (Strengthening Evidence for Programming on Unintended Pregnancy) Research Programme Consortium generates policy-relevant research to promote an evidence-based approach for improving access to family planning and safe abortion. STEP UP focuses its activities in five countries: Bangladesh, Ghana, India, Kenya, and Senegal.

STEP UP is coordinated by the Population Council in partnership with the African Population and Health Research Center; icddr,b; the London School of Hygiene and Tropical Medicine; and Marie Stopes International. STEP UP is funded by UK aid from the UK Government. 